University of Nebraska - Lincoln

DigitalCommons@University of Nebraska - Lincoln

Agronomy \& Horticulture -- Faculty Publications

Agronomy and Horticulture Department

2008

\title{
Modeling Responses of Dryland Spring Triticale, Proso Millet and Foxtail Millet to Initial Soil Water in the High Plains
}

\author{
S. A. Saseendran \\ Agricultural Systems Research Unit, USDA-ARS, Fort Collins, CO \\ D. C. Nielsen \\ Central Great Plains Research Station, USDA-ARS, 40335 County Road GG, Akron, CO \\ Drew J. Lyon \\ University of Nebraska-Lincoln, drew.lyon@wsu.edu \\ L. Ma \\ Agricultural Systems Research Unit, USDA-ARS, Fort Collins, CO \\ D. D. Baltensperger \\ Texas A\&M University, College Station, dbaltensperger@tamu.edu
}

See next page for additional authors

Follow this and additional works at: https://digitalcommons.unl.edu/agronomyfacpub

Part of the Plant Sciences Commons

Saseendran, S. A.; Nielsen, D. C.; Lyon, Drew J.; Ma, L.; Baltensperger, D. D.; Hoogenboom, G.; and Ahuja, L.R., "Modeling Responses of Dryland Spring Triticale, Proso Millet and Foxtail Millet to Initial Soil Water in the High Plains" (2008). Agronomy \& Horticulture -- Faculty Publications. 326.

https://digitalcommons.unl.edu/agronomyfacpub/326

This Article is brought to you for free and open access by the Agronomy and Horticulture Department at DigitalCommons@University of Nebraska - Lincoln. It has been accepted for inclusion in Agronomy \& Horticulture -Faculty Publications by an authorized administrator of DigitalCommons@University of Nebraska - Lincoln. 


\section{Authors}

S. A. Saseendran, D. C. Nielsen, Drew J. Lyon, L. Ma, D. D. Baltensperger, G. Hoogenboom, and L.R. Ahuja 


\title{
Modeling responses of dryland spring triticale, proso millet and foxtail millet to initial soil water in the High Plains
}

\author{
S.A. Saseendran ${ }^{\text {a }}$, D.C. Nielsen ${ }^{\text {b,* }}$, D.J. Lyon $^{\text {c }}$, L. Ma ${ }^{\text {a }}$, D.G. Felter ${ }^{\text {d }}$, D.D. Baltensperger ${ }^{\mathrm{e}}$, \\ G. Hoogenboom ${ }^{\text {f }}$ L.R. Ahuja ${ }^{\text {a }}$ \\ a Agricultural Systems Research Unit, USDA-ARS, Fort Collins, CO 80526, USA \\ ${ }^{\mathrm{b}}$ Central Great Plains Research Station, USDA-ARS, 40335 County Road GG, Akron, CO 80720, USA \\ ' University of Nebraska-Lincoln, Panhandle Res. E' Ext. Ctr., 4502 Ave. I, Scottsbluff, NE 69361, USA \\ ${ }^{\mathrm{d}}$ John Deere, 8000 Jersey Ridge Road, Davenport, IA 52807, USA \\ ${ }^{\mathrm{e}}$ Department of Soil and Crop Sciences, Texas A\&M University, 370 Olsen Blvd., College Station, TX 77843-2474, USA \\ ${ }^{\mathrm{f}}$ Department of Biological and Agricultural Engineering, College of Agricultural and Environmental Sciences, The University of Georgia, Griffin, GA 30223, USA
}

\section{A R T I C L E I N F O}

\section{Article history:}

Received 31 October 2008

Received in revised form 9 March 2009

Accepted 10 April 2009

\section{Keywords:}

Biomass

Crop simulation

DSSAT

Leaf area

Millet

Modeling

RZWQM

Soil water

Triticale

Yield

\begin{abstract}
A B S T R A C T
Dryland farming strategies in the High Plains must make efficient use of limited and variable precipitation and stored water in the soil profile for stable and sustainable farm productivity. Current research efforts focus on replacing summer fallow in the region with more profitable and environmentally sustainable spring and summer crops. In the absence of reliable precipitation forecasts for the crop growing season, farmers rely mainly upon knowledge of plant available water (PAW) in the soil profile at planting for making crop choice decisions. To develop a decision support strategy for crop selection based on initial PAW, experiments were conducted with spring triticale ( $X$ Titicosecale Wittmack), proso millet (Panicum miliaceum L.), and foxtail millet (Setaria italica L. Beauv.) under artificially controlled Low, Medium, and High initial PAW levels during 2004 and 2005 at Akron, Colorado, and Sidney, Nebraska. The objectives of this study were to adapt an existing cropping systems model for the simulation of triticale and millet and to evaluate simulations from the adapted model by comparing results with field data collected under varying initial PAW conditions. The Root Zone Water Quality Model with DSSAT v4.0 crop growth modules (RZWQM2) was used. Specifically, the Cropping System Model (CSM)-CERES-Wheat module was adapted for simulating triticale, and CSM-CERESSorghum (v4.0) module was adapted for simulating proso millet and foxtail millet. Soil water, leaf area index, grain yield, and biomass data for the highest PAW treatment from one crop season for each of the three crops were used to adapt and calibrate the crop modules. The models were then evaluated with data from the remaining PAW treatments. The proso millet module was further tested with four years of data from a crop rotation experiment at Akron from 2003 to 2006. Simulation results indicated that the adapted and calibrated crop modules have the potential to simulate these new crops under a range of varying water availability conditions. Consequently, these models can aid in the development of decision support tools for the season-to-season management of these summer fallow replacement crops under dryland conditions in semi-arid environments.
\end{abstract}

Published by Elsevier B.V.

\section{Introduction}

Profit margins for the production of most rainfed crops in the semi-arid climate of the Great Plains of the USA are very small (Clarke and Rendell, 2003; DeVuyst and Halvorson, 2004; Dhuyvetter et al., 1996; Meko and Woodhouse, 2005) due to frequent and extended episodes of severe drought. Farmers in the semi-arid Great Plains have traditionally used long periods of

\footnotetext{
* Corresponding author. Tel.: +1 970345 0507; fax: +1 9703452088 .

E-mail address: david.nielsen@ars.usda.gov (D.C. Nielsen).
}

fallow in a wheat (Triticum aestivum L.)-fallow cropping system to conserve soil water for the wheat crop and to stabilize production. The fallow system relies on the principle that leaving the land bare over a period of time allows water to accumulate in the soil. While this practice does indeed help stabilize crop yield, more intensified cropping systems, made possible with no-tillage practices that conserve residue cover, have been found to be more beneficial in terms of their increased precipitation storage efficiency, production, soil carbon sequestration, and decreased water and wind erosion potentials (Farahani et al., 1998; Halvorson et al., 2002a,b; Lal et al., 1998; Nielsen and Aiken, 1998; Nielsen et al., 2005; Peterson et al., 1998; Peterson and Westfall, 2004). Efforts are 
being made to develop viable cropping system alternatives to the conventional wheat-fallow (WF) system in terms of choice of the right crops in the rotation and their sequencing for maximizing profits and environmental sustainability (Anderson et al., 1999; Felter et al., 2006; Halvorson, 1990). Identification of profitable short-season spring crops to replace or shorten the fallow period in the cropping systems of the Great Plains have been the focus of several past studies (Felter et al., 2006; Lyon et al., 2004, 2007). Short-season crops such as spring triticale, dry pea (Pisum sativum L.), foxtail millet, and proso millet could be incorporated in crop rotations to replace summer fallow. Impacts of soil water depletion by one crop on the subsequent crop can vary significantly between seasons depending on the seasonal precipitation received (Nielsen et al., 1999, 2002; Nielsen and Vigil, 2005). Cropping intensification by replacing summer fallow with a crop can reduce subsequent crop yield (i.e., wheat). This reduction comes as a consequence of lower available soil water at planting of the subsequent crop (Nielsen et al., 2002). Long-term experiments are required to determine the response of summer fallow replacement crops under combinations of widely ranging available soil water at planting and seasonal precipitation scenarios. However, this is not economical to do, and furthermore the data will be site-specific. A viable alternative to long-term experiments at multiple locations is to simulate the cropping system using agricultural simulation models and to extrapolate short-term experimental results to other soils, seasons, and climates using location specific long-term weather data (Saseendran et al., 2004, 2005a, b; Elliott and Cole, 1989; Mathews et al., 2002). For developing such applications, crop simulation modules for the crops of interest need be developed, calibrated, and tested thoroughly for their performance under the climate of the region.

The Root Zone Water Quality Model (RZWQM), developed by USDA-ARS, is a process-oriented agricultural system model that integrates and synthesizes the biological, physical, and chemical processes for simulation of the impacts of tillage, water, agricultural chemical, and crop management practices on crop production and water quality (Ahuja et al., 2000). The generic crop model included in RZWQM can be parameterized to simulate specific crops. The Decision Support System for Agrotechnology Transfer (DSSAT) software provides modules for simulating more than 25 crops (Hoogenboom et al., 1999; Jones et al., 2003; Tsuji et al., 1994). Compared with the generic crop model of RZWQM, these crop modules simulate detailed leaf numbers, phenological and morphological development of the crop, and ultimately yield and yield components. The plant growth modules of DSSAT v3.5 were coupled with the soil water and nitrogen simulation routines of RZWQM to develop the RZWQM-DSSAT hybrid model (Ma et al., 2005, 2006). Advantages of using the RZWQM-DSSAT hybrid model come from combining the detailed simulations of soil surface residue dynamics, tillage, and other soil management practices, and detailed soil water and soil carbon/nitrogen processes of RZWQM with the detailed crop specific plant growth models of DSSAT. Recently, the crop modules of the RZWQMDSSAT hybrid model were upgraded with crop modules of DSSAT v4.0 Cropping System Model (CSM) and developed as RZWQM2DSSAT v4.0 (available at http://www.arsagsoftware.ars.usda.gov/ agsoftware/).

Various studies verifying the potential of applying RZWQM (Ahuja et al., 2000) for managing dryland cropping systems in the Great Plains have been reported. Saseendran et al. (2004) adapted RZWQM for simulating winter wheat and developed N management strategies based on the simulation results. Ma et al. (2003) successfully modeled the effects of varying levels of irrigation on corn production in the region. Using both RZWQM and CERESMaize (separately) Saseendran et al. (2005a) modeled planting date effects on corn production and developed optimum planting windows for the crop. Saseendran et al. (2005b) used RZWQM to successfully model dryland production systems involving rotations of corn, wheat, and fallow under conventional tillage and notillage in the semi-arid Great Plains.

In 2004 and 2005, experiments were conducted at Akron, CO and Sidney, NE to measure crop growth data for modeling four short-season summer fallow replacement crops (spring triticale, proso millet, foxtail millet, pea) under varying initial plant available water (PAW) conditions (Felter et al., 2006). The first objective of the current study was to simulate the effects of varying initial PAW at on growth, development, yield, and soil water extraction of the grass crops in that experiment (spring triticale, proso millet, and foxtail millet) by adapting crop simulation modules available in RZWQM2-DSSAT v4.0. The CSM-CERESWheat v4.0 crop module was adapted for simulating spring triticale, and the CSM-CERES-Sorghum v.4.0 crop module was adapted for simulation of both proso and foxtail millets. The second objective was to test the adapted models using fieldobserved data collected under varying PAW conditions.

\section{Materials and methods}

\subsection{Experiments}

Field experiments were conducted in 2004 and 2005 at the University of Nebraska High Plains Agricultural Laboratory $\left(41^{\circ} 12^{\prime} \mathrm{N}, 103^{\circ} 0^{\prime} \mathrm{W}, 1315 \mathrm{~m}\right.$ elevation) located near Sidney, NE and at the USDA-ARS Central Great Plains Research Station $\left(40^{\circ} 09^{\prime} \mathrm{N}, 103^{\circ} 09^{\prime} \mathrm{W}, 1383 \mathrm{~m}\right.$ elevation) located near Akron, CO. The soil type at Sidney was a Keith silt loam (fine-silty, mixed, superactive, mesic Aridic Argiustolls) with a pH of 7.0 and an organic matter content of approximately $20 \mathrm{~g} \mathrm{~kg}^{-1}$ in the surface $15 \mathrm{~cm}$. At Akron the soil type was a Weld silt loam (fine, smectitic, mesic Aridic Argiustolls) with a pH of 7.0 and an organic matter content of about $15 \mathrm{~g} \mathrm{~kg}^{-1}$ in the surface $15 \mathrm{~cm}$.

A split plot experimental design with four replications per field site was used at both locations. Three levels (Low, Medium, High) of available soil water at planting (PAW) served as the main plot treatments. The three summer annual crops (spring triticale, proso millet, and foxtail millet) were the subplot treatments. The three PAW treatments were established prior to planting with a lateral move drop-nozzle irrigation system, with the exception of Akron in 2005, when a solid-set sprinkler system was used. The Low PAW treatment received no supplemental water prior to planting. Amount of pre-plant irrigation water applied in the Medium and High water treatments varied by year and location, and was applied to achieve a range of soil water levels at planting. Planting and harvesting dates and initial PAW levels for each crop are shown in Tables 1 and 2 .

Soil water content was measured at approximately 14-d intervals. Measurements in the $0-30 \mathrm{~cm}$ layer were obtained by gravimetric water sampling at Sidney and by time-domain reflectometry (Trase System I, Soil Moisture Equipment Corporation, Santa Barbara, CA, USA) at Akron. Soil water content measurements at 45,75 , and $105 \mathrm{~cm}$ profile depths were made using a neutron probe (Campbell Pacific 503 DR, Campbell Pacific, Pacheco, CA, USA). Amount of plant available water was determined by subtracting lower limits of volumetric water from the total volumetric water content at each sampling depth. Lower limits at each site were determined from field observations of the lowest volumetric water content observed for these crops (Ritchie, 1981; Ratliff et al., 1983).

The water treatments were successfully established at both locations in 2004 for the triticale crop with $99 \mathrm{~mm}$ (Sidney) to $104 \mathrm{~mm}$ (Akron) more available soil water in the High treatment than in the Low treatment. Treatment establishment was also 
Table 1

Plant available water (PAW) in the upper $120 \mathrm{~cm}$ of the soil profile prior to planting for spring triticale, proso millet, and foxtail millet at Sidney, NE and Akron, CO.

\begin{tabular}{|c|c|c|c|c|c|c|c|c|c|c|}
\hline \multirow[t]{2}{*}{ Location } & \multirow[t]{2}{*}{ Year } & \multicolumn{3}{|c|}{ Spring triticale $(\mathrm{mm})$} & \multicolumn{2}{|c|}{ Proso millet $(\mathrm{mm})^{\mathrm{a}}$} & \multicolumn{4}{|c|}{ Foxtail millet $(\mathrm{mm})^{\mathrm{a}}$} \\
\hline & & Low & Medium & High & Low & Medium & High & Low & Medium & High \\
\hline \multirow[t]{2}{*}{ Sidney } & 2004 & 35 & 66 & 134 & - & - & - & - & - & - \\
\hline & 2005 & 134 & 154 & 174 & 212 & 228 & 244 & 212 & 228 & 244 \\
\hline \multirow[t]{2}{*}{ Akron } & 2004 & 64 & 127 & 168 & 90 & 140 & 190 & 98 & 132 & 161 \\
\hline & 2005 & 98 & 144 & 199 & - & - & - & - & - & - \\
\hline
\end{tabular}

${ }^{a}$ Foxtail and proso millet were lost to hail at Sidney in 2004, and soil crusting prevented emergence at Akron in 2005.

Table 2

Planting/harvest dates for spring triticale, proso millet and foxtail millet at Sidney, NE and Akron, CO.

\begin{tabular}{lllll}
\hline Location & Year & Spring triticale & Foxtail millet & Proso millet \\
\hline Sidney & 2004 & Apr 6/Jun 23 & - & - \\
& 2005 & Apr 7/Jun 24 & Jun 8/Aug 16 & Jun 8/Aug 30 \\
\multirow{2}{*}{ Akron } & 2004 & Apr 7/Jun 23 & Jun 2/Aug 26,30 & Jun 2/Aug 30 \\
& 2005 & Apr 4/Jun 24 & - & - \\
\hline
\end{tabular}

a At Akron in 2004, foxtail millet plots receiving the high level of supplemental water were harvested on August 26 as a result of more rapid crop development. The remaining foxtail millet plots were harvested on August 30.

successful for spring triticale in 2005 at Akron where the High treatment had $101 \mathrm{~mm}$ more PAW than the Low treatment. A smaller range in available soil water at planting was established at Sidney in 2005 for the three crops as a result of above normal precipitation.

Nutrient needs were based on regional recommendations. No supplemental fertilizer was applied in either year at Sidney. At
Akron, $67.2 \mathrm{~kg} \mathrm{~N} \mathrm{ha}^{-1}$ was applied on the surface beside each row and $22.4 \mathrm{~kg} \mathrm{ha}^{-1} \mathrm{P}_{2} \mathrm{O}_{5}$ was applied in the row at planting for spring triticale, foxtail millet, and proso millet in both years.

All crops were no-till seeded into corn stubble. Row spacing was $25 \mathrm{~cm}$ at Sidney and $19 \mathrm{~cm}$ at Akron. Planting dates are shown in Table 2. Spring triticale 'Trical 2700' was sown at $101 \mathrm{~kg}$ seed ha ${ }^{-1}$ 'White Wonder' foxtail millet and 'Sunrise' proso millet were sown at $17 \mathrm{~kg}$ seed ha ${ }^{-1}$. Proso and foxtail millet crops were lost to hail in late July at Sidney in 2004. Establishment of these crops was unsuccessful at Akron in 2005 due to soil crusting and subsequent dry surface soil conditions. Weeds were controlled by handweeding during the cropping season and glyphosate [ $\mathrm{N}$-(phosphonomethyl) glycine] was used during non-crop periods.

Leaf area index (LAI) and dry matter measurements were made a minimum of three times throughout each growing season. Leaf area index was estimated using a plant canopy analyzer (LAI-2000, LI-COR, Lincoln, NE, USA) with the $270^{\circ}$ view restrictor to mask the operator (i.e., $270^{\circ}$ open, $90^{\circ}$ masked). One measurement above and four below the canopy were taken twice in each plot to

Table 3

Measured (M) and simulated (S) phenology for spring triticale, proso millet, and foxtail millet grown at Sidney, NE and Akron, CO.

\begin{tabular}{|c|c|c|c|c|c|c|c|c|c|c|}
\hline \multirow[t]{3}{*}{ Location } & \multirow[t]{3}{*}{ Year } & \multicolumn{3}{|l|}{ Triticale } & \multicolumn{3}{|l|}{ Proso millet } & \multicolumn{3}{|l|}{ Foxtail millet } \\
\hline & & \multirow[b]{2}{*}{ Stage } & \multicolumn{2}{|c|}{ DAP } & \multirow[b]{2}{*}{ Stage } & \multicolumn{2}{|c|}{ DAP } & \multirow[b]{2}{*}{ Stage } & \multicolumn{2}{|l|}{ DAP } \\
\hline & & & $\mathrm{M}$ & $\mathrm{S}$ & & M & $\mathrm{S}$ & & M & $\mathrm{S}$ \\
\hline Sidney & 2004 & $\begin{array}{l}\text { Planting (Apr 6) } \\
\text { Emergence } \\
\text { Boot swollen } \\
\text { Head visible }\end{array}$ & $\begin{array}{l}13 \\
65 \\
70\end{array}$ & 12 & & & & & & \\
\hline Sidney & 2005 & $\begin{array}{l}\text { Planting (Apr 7) } \\
\text { Emergence } \\
\text { Head visible }\end{array}$ & $\begin{array}{l}18 \\
75\end{array}$ & 12 & $\begin{array}{l}\text { Planting (June 8) } \\
\text { Emergence } \\
\text { Head visible } \\
\text { Head fully emerged }\end{array}$ & $\begin{array}{r}5 \\
49 \\
64\end{array}$ & 7 & $\begin{array}{l}\text { Planting (June 8) } \\
\text { Emergence } \\
\text { Head visible } \\
\text { Head fully emerged }\end{array}$ & $\begin{array}{r}0 \\
5 \\
57 \\
68\end{array}$ & 7 \\
\hline Akron & 2004 & $\begin{array}{l}\text { Planting (Apr 7) } \\
\text { Emergence } \\
\text { Jointing } \\
\text { Awns visible } \\
\text { Anthesis }\end{array}$ & $\begin{array}{l}12 \\
53 \\
68 \\
77\end{array}$ & $\begin{array}{l}11 \\
69\end{array}$ & $\begin{array}{l}\text { Planting (June 2) } \\
\text { Emergence } \\
\text { Head visible } \\
\text { Head fully emerged } \\
\text { Anthesis } \\
\text { Early dough } \\
\text { Phys. Mat. }\end{array}$ & $\begin{array}{r}0 \\
10 \\
50 \\
64 \\
70 \\
79 \\
89\end{array}$ & $\begin{array}{l}10 \\
77 \\
93\end{array}$ & $\begin{array}{l}\text { Planting (June 2) } \\
\text { Emergence } \\
\text { Flag leaf visible } \\
\text { Head visible } \\
50 \% \text { headed }\end{array}$ & $\begin{array}{r}0 \\
10 \\
58 \\
75^{\mathrm{a}} \\
85^{\mathrm{a}}\end{array}$ & 8 \\
\hline Akron & 2005 & $\begin{array}{l}\text { Planting (Apr 4) } \\
\text { Emergence } \\
\text { Jointing } \\
\text { Boot swollen } \\
\text { Head fully emerged }\end{array}$ & $\begin{array}{l}10 \\
60 \\
70 \\
76\end{array}$ & 12 & & & & & & \\
\hline Akron & 2004 & & & & $\begin{array}{l}\text { Planting (June 7) } \\
\text { Emergence }\end{array}$ & 15 & 15 & & & \\
\hline Akron & 2005 & & & & $\begin{array}{l}\text { Planting (June 10) } \\
\text { Emergence }\end{array}$ & 7 & 11 & & & \\
\hline Akron & 2006 & & & & $\begin{array}{l}\text { Planting (June 8) } \\
\text { Emergence }\end{array}$ & 19 & 13 & & & \\
\hline
\end{tabular}

$\mathrm{DAP}=$ days after planting.

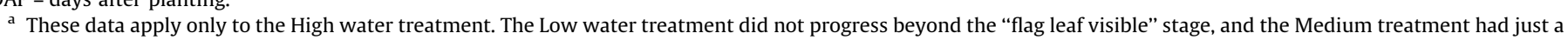
few heads visible at harvest (85 DAP). 
Table 4

Wheat ecotype parameters calibrated and adapted for simulation of spring triticale using the CSM-CERES-Wheat module.

\begin{tabular}{|c|c|}
\hline Acronym/Parameter & Value \\
\hline P1/Duration of phase end juvenile to double ridges, GDD & 200 \\
\hline P2/Duration of phase double ridges to end leaf growth, GDD & 265 \\
\hline P3/Duration of phase end leaf growth to end spike growth, GDD & 200 \\
\hline P4/Duration of phase end spike growth to end grain fill lag, GDD & 200 \\
\hline P4SGE/Stem growth end stage, growth stage. & 4.45 \\
\hline PARUV/PAR conversion to dry matter ratio before last leaf stage, g/MJ & 2.7 \\
\hline PARUR/PAR conversion to dry matter ratio after last leaf stage, $\mathrm{g} / \mathrm{MJ}$ & 2.7 \\
\hline AWNS/AWN score $(0-10 ; 10=$ very long $)$ & 0.0 \\
\hline LA1S/Area of standard first leaf, $\mathrm{cm}^{2}$ & 1.0 \\
\hline LAVS/Area of standard vegetative phase leaf, $\mathrm{cm}^{2}$ & 10.0 \\
\hline LARS/Area of standard reproductive phase leaf, $\mathrm{cm}^{2}$ & 40.0 \\
\hline LAWRS/Lamina area to weight ratio of standard first leaf, $\mathrm{cm}^{2} / \mathrm{g}$ & 200 \\
\hline LAWR2/Lamina area to weight ratio phase $2, \mathrm{~cm}^{2} / \mathrm{g}$ & 270 \\
\hline LLIFE/Life of leaves during vegetative phase, phyllochrons & 8.0 \\
\hline RSFRS/Reserves fraction of assimilates goir & 0.3 \\
\hline TI1LF/Tillering threshold (leaf No. to start tillering), No. & 4.0 \\
\hline GRNMN/Minimum grain $N$, \% & 0.0 \\
\hline GRNS/Standard grain $N, \%$ & 3.0 \\
\hline WFPU/Water stress factor (photosynthesis, upper), fraction & 1.2 \\
\hline WFGU/Water stress factor (growth, upper), fraction & 1.8 \\
\hline NFPU/N stress factor (photosynthesis, upper), fraction & 1.0 \\
\hline NFPL/N stress factor (photosynthesis, lower), fraction & 0.0 \\
\hline NFGU/N stress factor (growth, upper), fraction & 1.0 \\
\hline NFGL/N stress factor (growth, lower), fraction & 0.0 \\
\hline WFPGF/Water factor, genotype sensitivity to stress when grain filling (0-1) & 1.0 \\
\hline RDGS1/Root depth growth rate, early phase, $\mathrm{cm} / \mathrm{standard}$ day & 3.0 \\
\hline RDGS2/Root depth growth rate, later phases, $\mathrm{cm} /$ standard day & 2.0 \\
\hline TBGF/Temperature base, grain filling, ${ }^{\circ} \mathrm{C}$ & 5.0 \\
\hline P1DPE/Daylength factor, pre-emergence, No. (0-1) & 0.0 \\
\hline HTSTD/Standard canopy height, cm & 100 \\
\hline KCAN/PAR extinction coefficient, frac & 0.65 \\
\hline LT50H/Cold tolerance when fully hardened, ${ }^{\circ} \mathrm{C}$ & -20 \\
\hline
\end{tabular}

Table 5

Wheat species parameters calibrated and adapted for simulation of spring triticale using the CSM-CERES-Wheat module.

\begin{tabular}{lll}
\hline Acronym/Parameter & \multicolumn{2}{l}{ Value } \\
\cline { 2 - 3 } & Wheat & Triticale \\
\hline $\begin{array}{l}\text { LSENS/Leaf senescence X-stage (normal), No. } \\
\begin{array}{l}\text { LRETS/Stage after which dead leaves retained, } \\
\text { growth stage }\end{array}\end{array}$ & 5.7 & 5.9 \\
$\begin{array}{l}\text { WFSU/Water stress factor (senescence, upper), } \\
\quad \text { fraction }\end{array}$ & 0.6 & 5.0 \\
$\begin{array}{l}\text { WFSF/Water stress factor (fraction lost), fraction } \\
\text { NFS }\end{array}$ & 0.02 & 0.2 \\
\hline
\end{tabular}

determine LAI, with the four below measurements taken on a diagonal transect between crop rows. Dry matter sample size was $1 \mathrm{~m}$ of linear row, and the sample site was separated by at least one row from previously sampled areas. Samples were then oven-dried at $50{ }^{\circ} \mathrm{C}$ until weight remained constant.

Daily weather data (precipitation, air temperature, relative humidity, wind speed, and solar radiation) were recorded by automated weather stations located adjacent to the plot areas and
Table 6

Sorghum ecotype parameters calibrated and adapted for simulation of proso millet and foxtail millet using the CSM-CERES-Sorghum module.

\begin{tabular}{lc}
\hline Acronym/Parameter & Value \\
\hline $\begin{array}{l}\text { TBASE/Base temperature below which no development } \\
\text { occurs, }{ }^{\circ} \mathrm{C}\end{array}$ & 10 \\
$\begin{array}{l}\text { TOPT/Temperature at which maximum development } \\
\text { rate occurs during vegetative stages, }{ }^{\circ} \mathrm{C}\end{array}$ & 30 \\
$\begin{array}{l}\text { ROPT/Temperature at which maximum development } \\
\text { rate occurs for reproductive stages, }{ }^{\circ} \mathrm{C}\end{array}$ & 35 \\
$\begin{array}{l}\text { DJTI/Minimum days from end of juvenile stage to tassel } \\
\text { initiation if the cultivar is not photoperiod sensitive, days }\end{array}$ & 82 \\
$\begin{array}{l}\text { GDDE/Growing degree days per cm seed depth required } \\
\text { for emergence, GDD/cm }\end{array}$ & 8 \\
$\begin{array}{l}\text { RUE/Radiation use efficiency, } \text { g plant dry matter/MJ PAR } \\
\text { KCAN/Canopy light extinction coefficient for daily PAR }\end{array}$ & 3.2 \\
$\begin{array}{l}\text { P3/Duration of phase end leaf growth to end spike growth, TU } \\
\text { P4/Duration of phase end spike growth to end grain fill lag, TU }\end{array}$ & 0.85 \\
\hline
\end{tabular}

\footnotetext{
a $\mathrm{GDD}=$ growing degree days.

b $\mathrm{PAR}=$ photosynthetically active radiation.

c $\mathrm{TU}=$ thermal units.
}

retrieved from the High Plains Regional Climate Center (http:// www.hprcc.unl.edu/index.html).

Crop phenology notes were taken for major developmental stages in the crops and are shown in Table 3. No significant water treatment effects on growth stage progression were noted, except in 2004 for triticale at Sidney and foxtail millet at Akron. At harvest at Sidney in 2004 triticale was 20\%, 50\%, and $90 \%$ headed in the Low, Medium, and High water treatments, respectively (Felter et al., 2006). At Akron in 2004 foxtail millet in the Low water treatment did not progress beyond the "flag leaf visible" stage, and the Medium treatment had just a few heads visible at harvest.

\subsection{Crop model adaptations}

Simulation models for spring triticale and proso and foxtail millets are lacking in the literature. There were no crop modules available for these crops in the DSSAT v4.0 suite of crop models (Jones et al., 2003; Hoogenboom et al., 2004), and thus not in RZWQM2-DSSAT v4.0. In this study, we made an attempt to adapt CSM-CERES-Wheat for simulating spring triticale, and CSMCERES-Sorghum for simulating both proso and foxtail millets. The modules of CSM from DSSAT Version 4.0 as implemented in RZWQM2-DSSAT v4.0 were used. To adapt and simulate the three crop species using the CSM crop modules, the species, ecotype, and cultivar specific parameter sets used for simulating specific crops and their cultivars were modified based on measured data or obtained from the literature. If measured or literature reported values for any of the above parameters for the crops were not available, crop parameter values for wheat were adjusted and used for simulating triticale and parameters for sorghum (Sorghum bicolor L. Moench) were adjusted and used for simulating both proso and foxtail millets (Tables 4-6).

Table 7

Soil property values used for simulations of spring triticale, proso millet and foxtail millet at Akron, CO and Sidney, NE.

\begin{tabular}{|c|c|c|c|c|c|}
\hline Soil layer ${ }^{\mathrm{a}}(\mathrm{cm})$ & Bulk density $\left(\mathrm{g} \mathrm{cm}^{-3}\right)$ & $\begin{array}{l}\text { Saturated hydraulic } \\
\text { conductivity. }\left(\mathrm{cm} \mathrm{h}^{-1}\right)\end{array}$ & $\begin{array}{l}0.03 \mathrm{MPa} \text { water } \\
\text { content }\left(\mathrm{cm}^{3} \mathrm{~cm}^{-3}\right)\end{array}$ & $\begin{array}{l}1.5 \mathrm{MPa} \text { water } \\
\text { content }\left(\mathrm{cm}^{3} \mathrm{~cm}^{-3}\right)\end{array}$ & $\begin{array}{l}\text { Saturated water } \\
\text { content }\left(\mathrm{cm}^{3} \mathrm{~cm}^{-3}\right)\end{array}$ \\
\hline \multicolumn{6}{|c|}{ Weld silt loam (fine, smectitic, mesic Aridic Argiustolls) at Akron, CO } \\
\hline $0-180$ & 1.32 & 0.68 & 0.1361 & 0.2855 & 0.5010 \\
\hline \multicolumn{6}{|c|}{ Keith silt loam (fine-silty, mixed, superactive, mesic Aridic Argiustolls) at Sidney, NE } \\
\hline $0-180$ & 1.32 & 0.38 & 0.1361 & 0.2855 & 0.5010 \\
\hline
\end{tabular}

\footnotetext{
a Soil profile divided into seven layers (0-15, 15-30, 30-60, 60-90, 90-120, 120-150, 150-180 cm).
} 


\subsubsection{Species and ecotype parameters for triticale}

Much less literature exists on the growth and development characteristics of spring triticale compared with information for its parental lines [wheat and rye (Secale cereale L.)] that can be directly used for developing crop specific parameters for simulation of the crop. However, Ewert et al. (1996) successfully simulated phenological development in winter triticale using a wheat crop simulation model (AFRCWHEAT2), although they acknowledged that progress in simulating the development of cereals is limited by lack of knowledge about plant physiology. Singer et al. (2007) reported radiation use efficiencies of winter triticale in the range of 2.84-3.28 $\mathrm{g} \mathrm{MJ}^{-1}$ across various plant densities (67170 plants $\mathrm{m}^{-2}$ ). We used a constant calibrated value of $2.7 \mathrm{~g} \mathrm{MJ}^{-1}$ 1 for RUE in the simulations (an ecotype parameter in the CERESWheat module). For simulation of spring triticale, a value of 0.65 for PAR extinction coefficient was found to give the best results. To calculate growing degree days (GDD) we used a uniform base temperature of $0{ }^{\circ} \mathrm{C}$ for all growth stages of the crop (Gallagher, 1979), similar to wheat. However, we used a base temperature of $5{ }^{\circ} \mathrm{C}$ for accumulation of GDD during grain filling as it improved the simulations. Based on the above information in the literature and through calibration, a new ecotype parameter set was developed for the simulations of spring triticale (Table 4). The species parameter set for wheat was used to simulate triticale after adjusting four of the parameters to the values shown in Table 5.

\subsubsection{Species and ecotype parameters for proso and foxtail millets}

Proso millet and foxtail millet are short-season summer annual small cereal crops with high water-use efficiency (C4 plants) and are well adapted to crop production systems in the semi-arid environment of the USA (Lyon and Baltensperger, 1993; Anderson, 1994). Information on detailed growth and development characteristics of the two millets is lacking in the literature. There have been only limited efforts reported to model these crop species in the past. In order to simulate cropping sequences that involved proso millet in the Great Plains, Andales et al. (2003) simulated proso millet by parameterizing a generic crop model (EPIC; Williams et al., 1989) available in the GPFARM farming system model by making best guess estimates for the generic crop simulation model parameters. In RZWQM2-DSSAT v4.0, crop modules are available for sorghum (CSM-CERES-Sorghum) and pearl millet (Pennisetum americanum L.) (CSM-CERES-Millet) that fall broadly in the millet family. We experimented with both the modules for modeling the proso and foxtail millets and found the CSM-CERES-Sorghum module better suited for simulation of the millets (results not presented). Anderson (1994) showed that proso millet development can be related to temperature by using
Table 8

Cultivar parameters (genetic coefficients) calibrated for simulation of triticale (cv. Trical 2700) using the CSM-CERES-Wheat module.

\begin{tabular}{|c|c|c|}
\hline No. & Acronym/Parameter & Value \\
\hline 1 & $\begin{array}{l}\text { P1V/Relative amount that development is slowed for each day } \\
\text { of unfulfilled vernalization, assuming that } 50 \text { days of } \\
\text { vernalization is sufficient for all cultivars, GDD }\end{array}$ & 5 \\
\hline 2 & $\begin{array}{l}\text { P1D/Relative amount that development is slowed when plants } \\
\text { are grown in a photoperiod } 1 \mathrm{~h} \text { shorter than the optimum } \\
\text { (which is considered to be } 20 \mathrm{~h} \text { ), GDD }\end{array}$ & 105 \\
\hline 3 & $\begin{array}{l}\text { P5/Relative grain filling duration based on thermal time } \\
\text { (degree days above a base temperature of } 1^{\circ} \mathrm{C} \text { ), where } \\
\text { each unit increase above zero adds } 20 \text { degree days to an } \\
\text { initial value of } 430 \text { degree days }\end{array}$ & 450 \\
\hline 4 & $\begin{array}{l}\text { G1/Kernel number per unit weight of stem (less leaf blades } \\
\text { and sheaths) plus spike at anthesis, } 1 / \mathrm{g}\end{array}$ & 30 \\
\hline 5 & G2/Kernel filling rate under optimum conditions, $\mathrm{mg} / \mathrm{day}$ & 35 \\
\hline 6 & $\begin{array}{l}\text { G3/Non-stressed dry weight of a single stem (excluding leaf } \\
\text { blades and sheaths) and spike when elongation ceases, } g\end{array}$ & 1 \\
\hline 7 & PHINT/Phyllochron interval, GDD & 60 \\
\hline
\end{tabular}

GDD calculated with a base temperature of $10{ }^{\circ} \mathrm{C}$. For simulation of both proso and foxtail millet crops we adopted this base temperature as it worked well for quantifying the effects of temperature on both photosynthesis and grain filling processes. Based on the available information in the literature and calibration, a new ecotype parameter set was developed for the simulations (Table 6). In addition to modifying the species and ecotype parameter files, we also made changes to the CSM-CERESSorghum v4.0 module. Growing degree days from germination to emergence (P9) is not calculated by CSM-CERES-Sorghum v4.0, but we calculated P9 using the relationship from CERES-Maize as

$\mathrm{P} 9=45.0+\mathrm{GDDE} \times \mathrm{SDEPTH}$

where GDDE (an ecotype parameter) is GDD per cm seed depth (SDEPTH) required for emergence.

In order to better match the simulated pattern of leaf area development with the observed pattern, the equation used for calculation of leaf senescence during crop development stage 3 (SLAN) was modified to

$\mathrm{SLAN}=1+50\left(\frac{\text { SUMDTT }}{\mathrm{P} 3}\right)^{2}$

where SUMDTT is GDDE accumulated starting from seedling emergence, $\mathrm{P} 3$ is the duration of the development phase from end of leaf growth to end of spike growth, and stage 3 is the period from panicle initiation to end of leaf growth.

Table 9

Cultivar parameters (genetic coefficients) calibrated for simulation of proso millet (cv. Sunrise) and foxtail millet (cv. White Wonder) using the CSM-CERES-Sorghum module.

\begin{tabular}{|c|c|c|c|}
\hline \multirow[t]{2}{*}{ No. } & \multirow[t]{2}{*}{ Acronym/Parameter } & \multicolumn{2}{|l|}{ Value } \\
\hline & & Proso millet & Foxtail millet \\
\hline 1 & $\begin{array}{l}\text { P1/Thermal time from seedling emergence to the end of the juvenile } \\
\text { phase during which the plant is not responsive to changes in photoperiod, GDD }\end{array}$ & 40.0 & 220 \\
\hline 2 & $\begin{array}{l}\text { P20/Critical photoperiod or the longest day length at which development } \\
\text { occurs at a maximum rate. At values higher than P20, the rate of development } \\
\text { is reduced, hours }\end{array}$ & 16.5 & 12.5 \\
\hline 3 & $\begin{array}{l}\text { P2R/Extent to which phasic development leading to panicle initiation is delayed } \\
\text { for each hour increase in photoperiod above P20, GDD }\end{array}$ & 20.0 & 40.0 \\
\hline 4 & $\begin{array}{l}\text { P5/Thermal time from beginning of grain filling (3-4 days after flowering) } \\
\text { to physiological maturity, GDD }\end{array}$ & 55.0 & 10.0 \\
\hline 5 & G1/Scaler for relative leaf size & 12.5 & 0.0 \\
\hline 6 & G2/Scaler for partitioning of assimilates to the panicle (head) & 7.5 & 0.0 \\
\hline 7 & $\begin{array}{l}\text { PHINT/Phyllochron interval; the interval between successive leaf tip } \\
\text { appearances, GDD }\end{array}$ & 35.0 & 56.0 \\
\hline
\end{tabular}

a Growing degree days above a base temperature of $10^{\circ} \mathrm{C}$. 


\subsection{Input data for the model}

The RZWQM2-DSSAT v4.0 model needs detailed data on weather and soil for the experimental site, and crop management data for the actual experiment. Typical crop management data needed are planting dates, planting depth, row spacing, and plant population. Also, the amounts, dates, and methods of irrigation, tillage and fertilizer applications, if any, are required. These data were collected at the experiment sites.

The minimum driving variables for the RZWQM2-DSSAT v4.0 are daily solar radiation, maximum and minimum air temperatures, wind speed, relative humidity, and precipitation (as break point rainfall data). All of the above variables were measured by an automated weather station located approximately $300 \mathrm{~m}$ from the experimental site. We assumed the daily precipitation to consist of storms of 120 min duration for both years and both locations (Sidney and Akron).

Soil physical and hydraulic properties for a silt loam soil as available in the RZWQM model database (Ahuja et al., 2000) were used for simulations of the three crops on the Weld silt loam and Keith silt loam soil types at Akron and Sidney, respectively (Tables 7 and 8). However, in order to achieve a better match between the measured and simulated soil water in the Keith silt loam soil at Sidney we calibrated and used a value of $0.38 \mathrm{~cm} \mathrm{~h}^{-1}$ for saturated hydraulic conductivity.

\subsection{Model calibration}

For adaptation and calibration of the crop modules, we used the crop growth and development data under the High water treatment for triticale and foxtail millet at Akron in 2004 and for proso millet at Sidney in 2005. Remaining data sets were used for model testing and evaluation. In addition to these data, similar data for proso millet growth, development, water use, and yield from the alterative crop rotation (ACR) experiment at Akron (Anderson et al., 1999) from 2003 to 2006 were used (Nielsen, unpublished data, 2006).

For accurate simulations, agricultural system models need to be calibrated for soil hydraulic and nutrient properties for given sites,
Table 10

Monthly and growing season precipitation (cm) for Sidney, NE and Akron, CO.

\begin{tabular}{llllrlll}
\hline Location & Year & Apr & May & June & July & Aug & Apr-Aug \\
\hline Sidney & 2004 & 5.5 & 2.6 & 6.6 & 6.7 & 4.1 & 25.5 \\
& 2005 & 5.4 & 5.0 & 15.4 & 6.0 & 6.3 & 38.1 \\
& $30-$ yr normal & 3.8 & 7.3 & 7.0 & 5.7 & 4.8 & 28.6 \\
\multirow{5}{*}{ Akron } & 2004 & 4.4 & 4.4 & 6.6 & 4.3 & 3.6 & 23.3 \\
& 2005 & 4.6 & 5.1 & 7.6 & 4.3 & 8.0 & 29.6 \\
& $30-$ yr normal & 3.6 & 7.6 & 5.8 & 7.5 & 5.7 & 30.2 \\
\hline
\end{tabular}

and plant growth parameters for given crops. Soil water simulations by the model for all three crops were mostly within one standard deviation of the measured means, such that we did not further calibrate the model hydraulic properties.

In the DSSAT v4.0 suite of crop models, in addition to the species and ecotype files (as derived above for triticale, proso millet, and foxtail millet) used for defining the broad crop characteristics, cultivar specific parameters (genetic coefficients) for defining the traits that differentiate between cultivars within a crop species are needed (Jones et al., 2003). Seven cultivar parameters specific to each of the crop cultivars used in the experiments needed to be calibrated (Tables 9 and 10). In this study, cultivar parameters (genetic coefficients) for the 'Trical 2700', 'Sunrise', and 'White Wonder' cultivars of spring triticale, proso millet, and foxtail millet, respectively, were calibrated through trial and error.

Soil water, LAI, biomass, and grain yield at harvest from the highest initial water treatments at Akron in 2004 (triticale, foxtail millet) and Sidney in 2005 (proso millet) were used for calibrations of the cultivar specific coefficients (Tables 8 and 9). Grain yield data for spring triticale and foxtail millet were not collected as they were harvested for forage before physiological maturity.

\subsection{Model evaluation statistics}

The following statistics were used to evaluate the simulation results: (i) Root Mean Square Error (RMSE), Eq. (3), which shows

Table 11

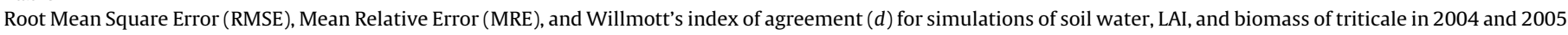
at Akron, CO and Sidney, NE in response to High, Medium, and Low plant available water (PAW) in the soil at planting.

\begin{tabular}{|c|c|c|c|c|c|c|c|c|c|}
\hline \multirow[t]{2}{*}{ Variables } & \multicolumn{3}{|l|}{ High PAW } & \multicolumn{3}{|c|}{ Medium PAW } & \multicolumn{3}{|c|}{ Low PAW } \\
\hline & RMSE & MRE, \% & $d$ & RMSE & MRE, \% & $d$ & RMSE & MRE, \% & $d$ \\
\hline \multicolumn{10}{|l|}{ Akron 2004} \\
\hline Soil water, $\mathrm{m}^{3} \mathrm{~m}^{-3}$ & $0.027^{\mathrm{a}}$ & - & - & 0.026 & - & - & 0.014 & - & - \\
\hline Soil profile water, $\mathrm{cm}$ & $0.7^{\mathrm{a}}$ & $3^{a}$ & $0.98^{\mathrm{a}}$ & 1.00 & 4 & 0.91 & 0.7 & 3 & 0.91 \\
\hline LAI, $\mathrm{m}^{2} \mathrm{~m}^{-2}$ & $0.27^{\mathrm{a}}$ & $14^{\mathrm{a}}$ & $0.98^{\mathrm{a}}$ & 0.29 & 22 & 0.95 & 0.16 & 9 & 0.92 \\
\hline Biomass, $\mathrm{kg} \mathrm{ha}^{-1}$ & $241^{\mathrm{a}}$ & $8^{a}$ & $1.0^{\mathrm{a}}$ & 309 & 11 & 0.99 & 328 & 19 & 0.96 \\
\hline \multicolumn{10}{|l|}{ Akron 2005} \\
\hline Soil water, $\mathrm{m}^{3} \mathrm{~m}^{-3}$ & 0.038 & - & - & 0.039 & - & - & 0.032 & - & - \\
\hline Soil profile water, $\mathrm{cm}$ & 3.3 & 10 & 0.81 & 4.7 & 17 & 0.54 & 4.2 & 15 & 0.61 \\
\hline LAI, $\mathrm{m}^{2} \mathrm{~m}^{-2}$ & 0.32 & 10 & 0.97 & 0.41 & 21 & 0.95 & 0.31 & 16 & 0.97 \\
\hline Biomass, $\mathrm{kg} \mathrm{ha}^{-1}$ & 180 & 7 & 1.00 & 379 & 19 & 0.99 & 309 & 12 & 0.99 \\
\hline \multicolumn{10}{|l|}{ Sidney 2004} \\
\hline Soil water, $\mathrm{m}^{3} \mathrm{~m}^{-3}$ & 0.032 & - & - & 0.034 & - & - & 0.025 & - & - \\
\hline Soil profile water, $\mathrm{cm}$ & 1.3 & 4 & 0.94 & 1.4 & 6 & 0.70 & 1.4 & 6 & 0.65 \\
\hline LAI, $\mathrm{m}^{2} \mathrm{~m}^{-2}$ & 0.37 & 23 & 0.94 & 0.25 & 23 & 0.95 & 0.27 & 31 & 0.92 \\
\hline Biomass, $\mathrm{kg} \mathrm{ha}^{-1}$ & 537 & 27 & 0.97 & 560 & 31 & 0.92 & 289 & 28 & 0.96 \\
\hline \multicolumn{10}{|l|}{ Sidney 2005} \\
\hline Soil water, $\mathrm{m}^{3} \mathrm{~m}^{-3}$ & 0.025 & - & - & 0.025 & - & - & 0.036 & - & - \\
\hline Soil profile water, $\mathrm{cm}$ & 1.2 & 4 & 0.93 & 1.2 & 4 & 0.96 & 2.9 & 11 & 0.79 \\
\hline LAI, $\mathrm{m}^{2} \mathrm{~m}^{-2}$ & 0.45 & 22 & 0.87 & 0.42 & 22 & 0.96 & 0.50 & 23 & 0.94 \\
\hline Biomass, $\mathrm{kg} \mathrm{ha}^{-1}$ & 500 & 16 & 0.99 & 450 & 10 & 0.99 & 258 & 9 & 0.99 \\
\hline
\end{tabular}

\footnotetext{
a Calibration results.
} 
the average deviation between simulated and observed values; (ii) Mean Relative Error (MRE), Eq. (4), which gives the bias of the simulated value relative to the observed value; and (iii) the index of agreement (d), Eq. (5) between measured and simulated parameters (Willmott, 1981), which varies between 0 (poor model) and 1 (perfect model):

$\mathrm{RMSE}=\sqrt{\frac{1}{n} \sum_{i=1}^{n}\left(P_{i}-O_{i}\right)^{2}}$

$\mathrm{MRE}=\frac{1}{n} \sum_{i=1}^{n} \operatorname{Abs}\left[\frac{\left.P_{i}-O_{i}\right)}{O_{i}}\right] \times 100$

$d=1.0-\frac{\sum_{i=1}^{n}\left(P_{i}-O_{i}\right)^{2}}{\sum_{i=1}^{n}\left(\left|P_{i}-\bar{O}\right|+\left|O_{i}-\bar{O}\right|\right)^{2}}$

where $P_{i}$ is the $i$ th simulated value, $O_{i}$ is the $i$ th observed value, $\bar{O}$ is the mean observed value, and $n$ is the number of data pairs.

\section{Results and discussion}

At Sidney, precipitation during the April to August period (Table 10) was $89 \%$ of normal $(28.6 \mathrm{~cm}, 1971-2000)$ in 2004 and $133 \%$ of normal in 2005. At Akron, precipitation was $77 \%$ of normal (30.2 cm, 1971-2000) in 2004 and 98\% of normal in 2005 for the same period. Despite some month-to-month variation, average daily temperatures for the April to August growing seasons in 2004 and 2005 were near normal (between 6.7 and $24.1^{\circ} \mathrm{C}$ ) at both locations (data not shown).

\subsection{Triticale}

\subsubsection{Calibration}

Calibrations of model parameters for accurate soil water simulations are critical for correct quantification of soil water stress that controls crop growth and development. At both Akron and Sidney, soil water measurements were available at approximately bi-weekly intervals for comparison with the model simulations. In the High water treatment in 2004 at Akron (calibration data set), $16.8 \mathrm{~cm}$ of PAW was available in the $120 \mathrm{~cm}$ soil profile at planting (Table 1 ) which served as the initial soil water content for the calibration of the model. Simulated volumetric soil water in the different layers during the 2004 triticale growing season corresponded well with measured values (RMSE $\left.=0.027 \mathrm{~m}^{3} \mathrm{~m}^{-3}\right)$. Total water in the $120 \mathrm{~cm}$ soil profile was also modeled well (RMSE $=0.7 \mathrm{~cm}, \mathrm{MRE}=3 \%, d=0.98$ ) (Table 11 , Fig. 1). We considered these calibration results to be adequate since RZWQM2-DSSAT v4.0 is a one dimensional model in which a single soil profile (point measurement) represents the average conditions in a heterogeneous field that is spatially variable in soil water content.

Triticale was harvested for forage on 23 June (immediately after anthesis), and as such the crop did not complete all the phenological stages and reach physiological maturity (Table 2). The simulated emergence date had an error of 1 day, and the

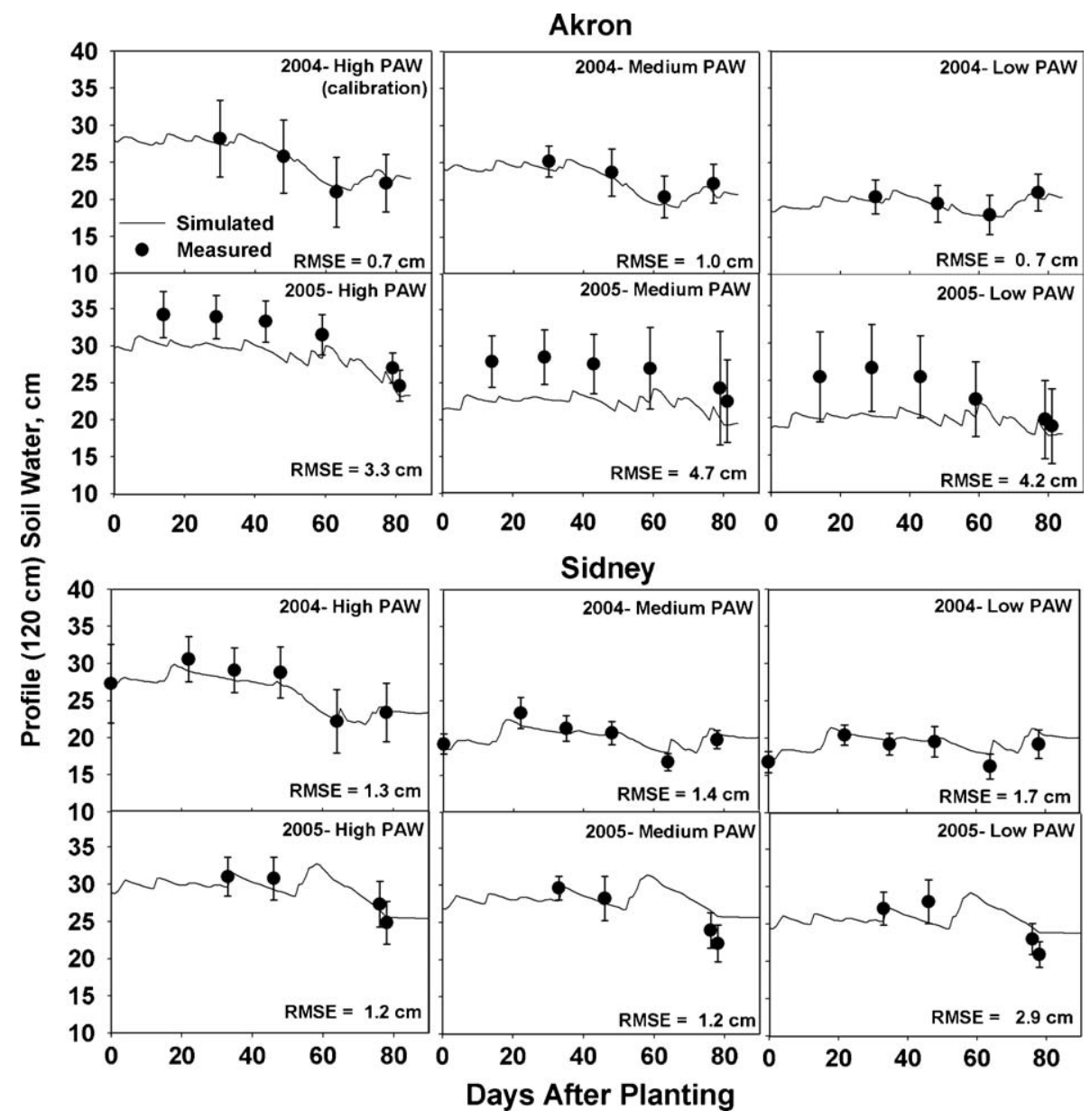

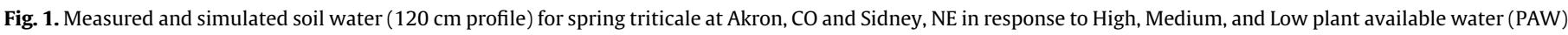
in the soil at planting in 2004 and 2005. Error bars represent one standard deviation of the mean. 
simulated anthesis date was 8 days earlier than measured (Table 3). LAI simulations had an RMSE of $0.27 \mathrm{~m}^{2} \mathrm{~m}^{-2}$, MRE of $14 \%$, and $d$ of 0.98 (Fig. 2, Table 11). Biomass progression (forage yield) with crop development was simulated with an RMSE of $241 \mathrm{~kg} \mathrm{ha}^{-1}$, MRE of $8 \%$, and $d$ of 1.0 (Table 11, Fig. 3). Calibration results showed that the model is capable of simulating spring triticale in the semi-arid climate of the High Plains with reasonable accuracy.

\subsubsection{Validation}

The calibrated triticale model was further tested with data from the Medium and Low PAW treatments at Akron in 2004, and High, Medium, and Low PAW treatments at Akron in 2005 and at Sidney in 2004 and 2005 (Table 1). Forage yield of spring triticale increased with increased PAW in 2004 at both Akron and Sidney, and the model simulations followed the trend well (Fig. 3). Biomass simulations in the Medium and Low PAW treatments at Akron in 2004 had RMSEs of $309 \mathrm{~kg} \mathrm{ha}^{-1}$ (MRE $=11 \%$ and $d=0.99$ ) and $328 \mathrm{~kg} \mathrm{ha}^{-1}(\mathrm{MRE}=19 \%$ and $d=0.96)$, respectively (Table 11 and Fig. 3). Also for the Medium and Low treatments at Akron in 2004 , simulations of volumetric soil water in different soil layers had RMSEs of 0.026 and $0.014 \mathrm{~m}^{3} \mathrm{~m}^{-3}$; total soil profile water had RMSEs of $1.0(\mathrm{MRE}=4 \%, d=0.91)$ and $0.7 \mathrm{~cm}(\mathrm{MRE}=3 \%, d=0.91)$; and LAI had RMSEs of $0.29 \mathrm{~m}^{2} \mathrm{~m}^{-2}(\mathrm{MRE}=22 \%, d=0.95)$ and $0.16 \mathrm{~m}^{2} \mathrm{~m}^{-2}(\mathrm{MRE}=9 \%, d=0.92)$, respectively (Table 11 , and Figs. 1-3).

Triticale biomass at Sidney in 2004 under all three PAW treatments was modeled reasonably well with RMSEs of biomass simulations ranging between $289 \mathrm{~kg} \mathrm{ha}^{-1}(\mathrm{MRE}=28 \%$ and $d=0.96$ ) (Low PAW treatment) and $560 \mathrm{~kg} \mathrm{ha}^{-1}(\mathrm{MRE}=31 \%$ and $d=0.92$ (Medium PAW treatment) (Table 11, Fig. 3). Volumetric soil water in different soil layers was simulated best for the Low PAW treatment $\left(\right.$ RMSE $=0.025 \mathrm{~m}^{3} \mathrm{~m}^{-3}$ ). Total soil profile water was simulated best for the High PAW treatment $($ RMSE $=1.3 \mathrm{~cm})$, and LAI was simulated best for the Medium PAW treatment $\left(\right.$ RMSE $=0.25 \mathrm{~m}^{2} \mathrm{~m}^{-2}$ ). Simulation RMSEs ranged between 0.025 and $0.034 \mathrm{~m}^{3} \mathrm{~m}^{-3}$ for volumetric soil water in different soil layers, 1.3 and $1.4 \mathrm{~cm}$ for total soil profile water, and 0.25 and $0.37 \mathrm{~m}^{2} \mathrm{~m}^{-2}$ for LAI (Table 11 , and Figs. 1-3).

In 2005, the measured biomass response to initial PAW was not significant at either location ( $P=0.75$, Sidney; $P=0.38$, Akron). This was presumably due to above average rainfall amounts (Table 10 ). Precipitation in June was $222 \%$ and $132 \%$ of normal for Sidney and Akron, respectively. This ample amount of precipitation during the crop's peak water requirement period reduced plant growth response to stored soil water reserves. The measured crop growth responses in 2005 at both Akron and Sidney were well simulated by the model (Fig. 3). Biomass simulations at Akron in 2005 under different PAW treatments had RMSEs between $180 \mathrm{~kg} \mathrm{ha}^{-1}$ $(\mathrm{MRE}=7 \%$ and $d=1.0)$ and $379 \mathrm{~kg} \mathrm{ha}^{-1}(\mathrm{MRE}=19 \%$ and $d=0.99)$ (Table 11, Fig. 3). LAI simulations showed RMSEs between $0.31 \mathrm{~m}^{2} \mathrm{~m}^{-2} \quad$ (MRE $=16 \%$ and $d=0.97$ ) and $0.41 \mathrm{~m}^{2} \mathrm{~m}^{-2}$ $(\mathrm{MRE}=21 \%$ and $d=0.95)$ (Table 11 and Fig. 2). Biomass simulations at Sidney in 2005 resulted in RMSEs between $258 \mathrm{~kg} \mathrm{ha}^{-1}$ $(\mathrm{MRE}=9 \%$ and $d=0.99)$ and $500 \mathrm{~kg} \mathrm{ha}^{-1}(\mathrm{MRE}=16 \%$ and $d=0.99)$

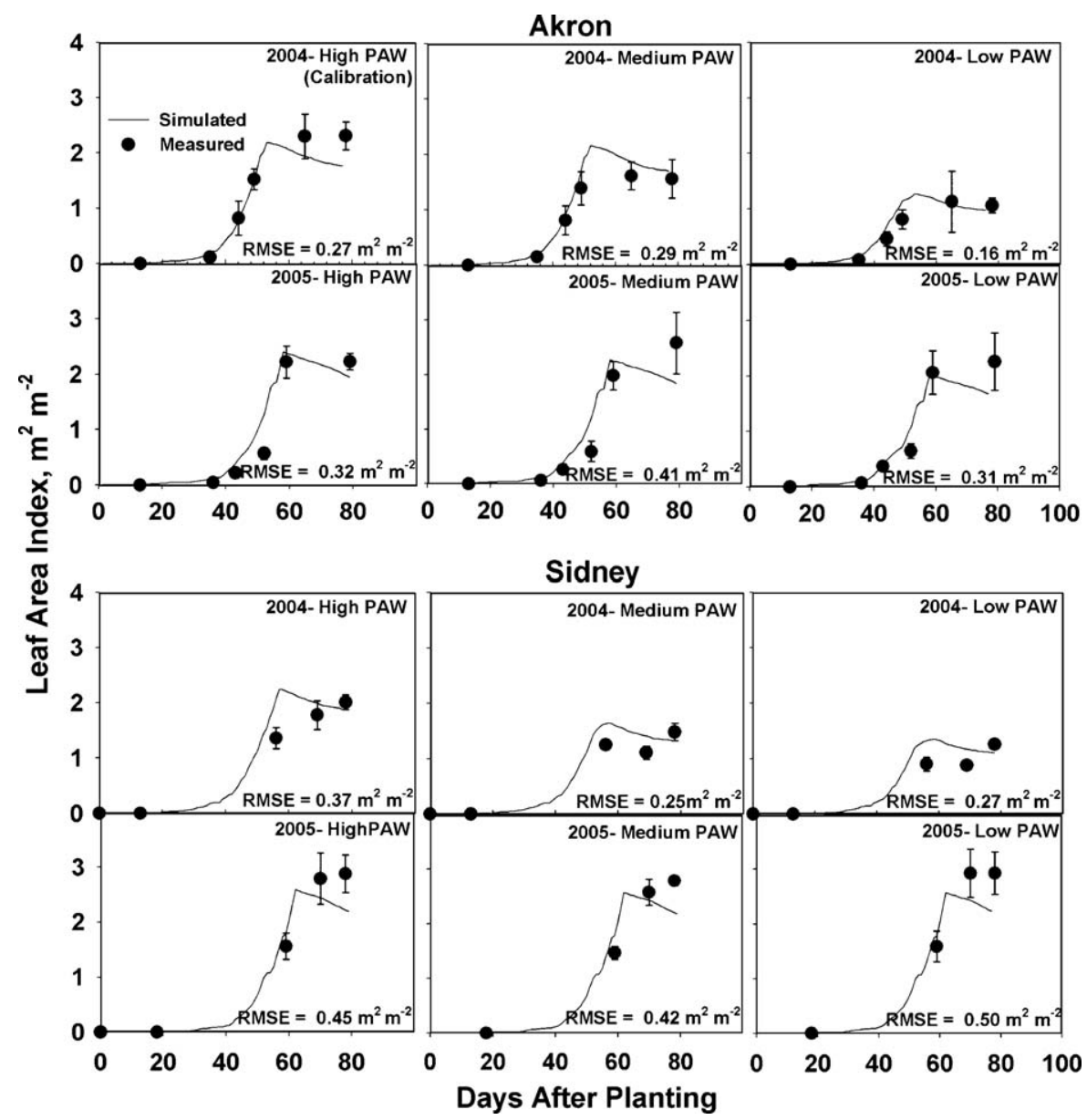

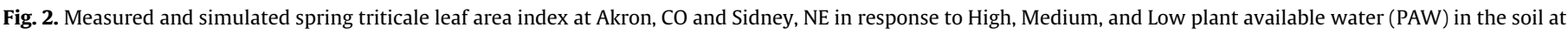
planting in 2004 and 2005. Error bars represent one standard deviation of the mean. 


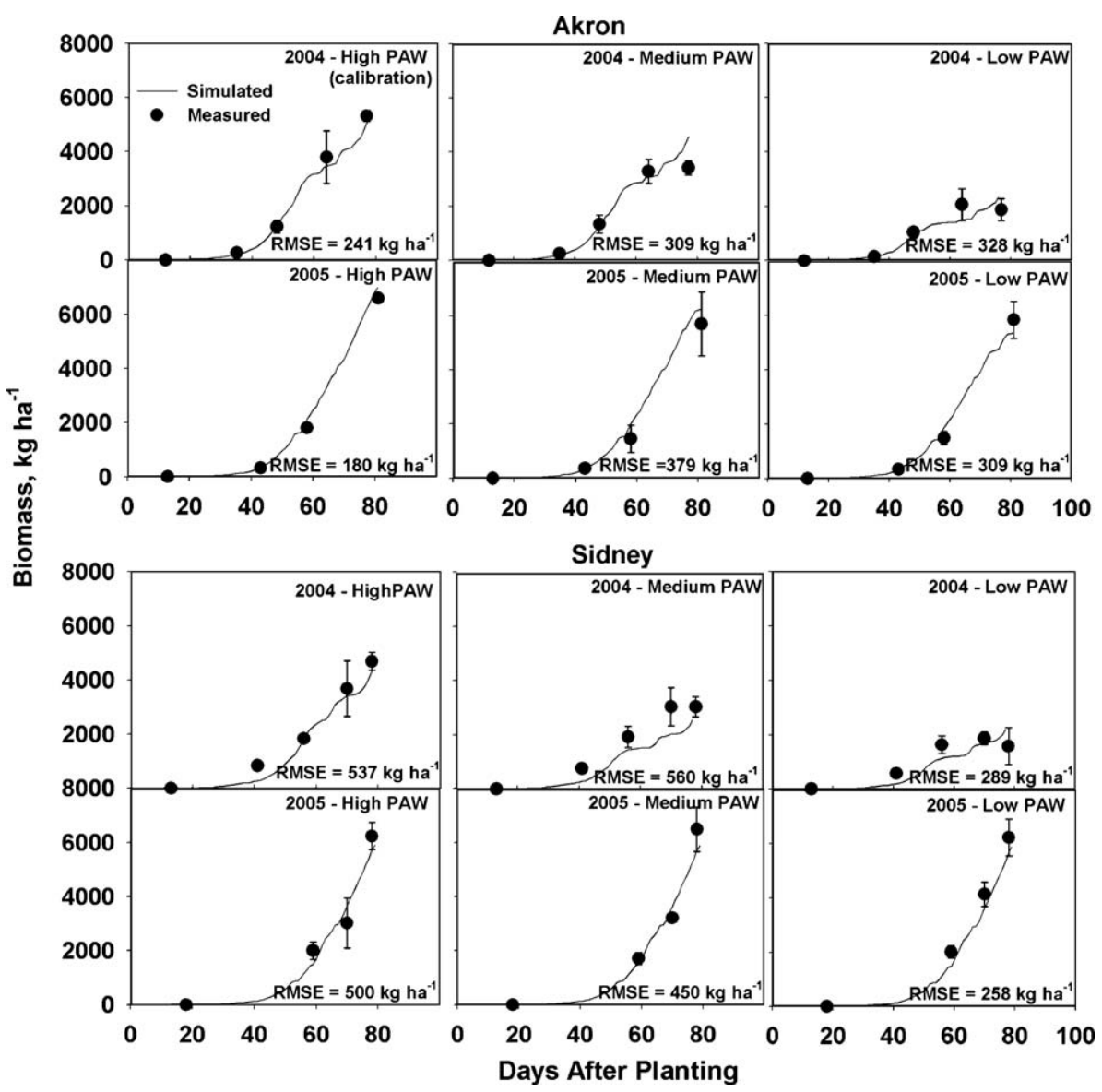

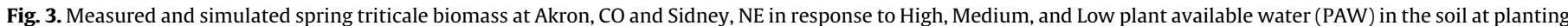
in 2004 and 2005. Error bars represent one standard deviation of the mean.

Table 12

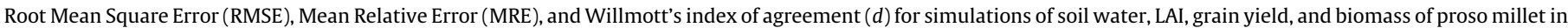

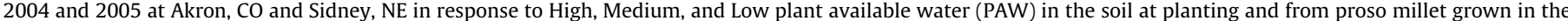
alternative crop rotation (ACR) experiments at Akron from 2003 to 2006.

\begin{tabular}{|c|c|c|c|c|c|c|c|c|c|}
\hline \multirow[t]{2}{*}{ Variables } & \multicolumn{3}{|l|}{ High PAW } & \multicolumn{3}{|c|}{ Medium PAW } & \multicolumn{3}{|l|}{ Low PAW } \\
\hline & RMSE & MRE, \% & $d$ & RMSE & MRE, \% & $d$ & RMSE & MRE, \% & $d$ \\
\hline \multicolumn{10}{|l|}{ Akron 2004} \\
\hline Soil water, $\mathrm{m}^{3} \mathrm{~m}^{-3}$ & 0.039 & - & - & 0.036 & - & - & 0.038 & - & - \\
\hline Soil profile water, $\mathrm{cm}$ & 1.9 & 6 & 0.92 & 2.5 & 7 & 0.75 & 2.0 & 7 & 0.62 \\
\hline LAI, $\mathrm{m}^{2} \mathrm{~m}^{-2}$ & 0.97 & 33 & 0.78 & 1.0 & 35 & 0.72 & 0.97 & 39 & 0.65 \\
\hline Grain yield, $\mathrm{kg} \mathrm{ha}^{-1}$ & 28 & 2 & - & 272 & 23 & - & 565 & 87 & - \\
\hline Biomass, $\mathrm{kg} \mathrm{ha}^{-1}$ & 588 & 30 & 0.98 & 955 & 29 & $0.9 \mathrm{~s} 5$ & 712 & 32 & 0.96 \\
\hline \multicolumn{10}{|l|}{ Sidney 2005} \\
\hline Soil water, $\mathrm{m}^{3} \mathrm{~m}^{-3}$ & $0.033^{\mathrm{a}}$ & - & - & - & - & - & 0.027 & - & - \\
\hline Soil profile water, $\mathrm{cm}$ & $2.2^{\mathrm{a}}$ & $8^{a}$ & $0.97^{\mathrm{a}}$ & 2.3 & 8 & 0.97 & 1.2 & 5 & 0.99 \\
\hline LAI, $\mathrm{m}^{2} \mathrm{~m}^{-2}$ & $0.83^{\mathrm{a}}$ & $21^{\mathrm{a}}$ & $0.92^{\mathrm{a}}$ & 0.86 & 36 & 0.92 & 0.90 & 38 & 0.91 \\
\hline Grain yield, $\mathrm{kg} \mathrm{ha}^{-1}$ & $428^{a}$ & $10^{\mathrm{a}}$ & - & 549 & 12 & - & 459 & 10 & - \\
\hline \multirow[t]{2}{*}{ Biomass, $\mathrm{kg} \mathrm{ha}^{-1}$} & $411^{\mathrm{a}}$ & $6^{a}$ & $1.00^{\mathrm{a}}$ & 791 & 10 & 0.99 & 1106 & 15 & 0.99 \\
\hline & \multicolumn{3}{|c|}{ ACR Akron 2003} & \multicolumn{3}{|c|}{ ACR Akron 2004} & \multicolumn{3}{|c|}{ ACR Akron 2005} \\
\hline Soil water, $\mathrm{m}^{3} \mathrm{~m}^{-3}$ & 0.068 & - & - & 0.058 & - & - & 0.070 & - & - \\
\hline Soil profile water, $\mathrm{cm}$ & 2.2 & 6 & 0.96 & 2.3 & 10 & 0.91 & 6.7 & 21 & 0.38 \\
\hline LAI, $\mathrm{m}^{2} \mathrm{~m}^{-2}$ & 0.41 & 21 & 0.93 & - & - & - & 0.89 & 40 & 0.80 \\
\hline Grain yield, $k g$ ha $^{-1}$ & 153 & 6 & - & 71 & 3 & - & 352 & 37 & - \\
\hline \multirow[t]{2}{*}{ Biomass, $\mathrm{kg} \mathrm{ha}^{-1}$} & 1603 & 80 & 0.85 & 1549 & 20 & 0.95 & 1030 & 19 & 0.94 \\
\hline & \multicolumn{3}{|c|}{ ACR Akron 2006} & & & & & & \\
\hline Soil water, $\mathrm{m}^{3} \mathrm{~m}^{-3}$ & 0.041 & - & - & & & & & & \\
\hline Soil profile water, $\mathrm{cm}$ & 2.2 & 9 & 0.95 & & & & & & \\
\hline LAI, $\mathrm{m}^{2} \mathrm{~m}^{-2}$ & 0.64 & 19 & 0.88 & & & & & & \\
\hline Grain yield, $\mathrm{kg} \mathrm{ha}^{-1}$ & 188 & 12 & - & & & & & & \\
\hline Biomass, $\mathrm{kg} \mathrm{ha}^{-1}$ & 868 & 22 & 0.97 & & & & & & \\
\hline
\end{tabular}

\footnotetext{
a Calibration results.
} 
(Table 11, Fig. 3). LAI simulations had RMSEs between 0.42 and $0.50 \mathrm{~m}^{2} \mathrm{~m}^{-2}$ (Table 11 and Fig. 2).

Measured soil water in 2005 at Akron across the treatments showed high variability between replications in all three treatments, indicated by high standard deviations from the mean (Table 11, Fig. 1). Interestingly, simulated soil water in this year showed greater errors compared to other years and locations. Across the three treatments, RMSEs of simulations of volumetric soil water in different soil layers varied between 0.032 and $0.039 \mathrm{~m}^{3} \mathrm{~m}^{-3}$; total soil profile water had RMSEs between $3.3 \mathrm{~cm}$ (MRE $=10 \%, d=0.81)$ and $4.7 \mathrm{~cm}(\mathrm{MRE}=17 \%, d=0.54)$. We have not been able to determine the cause of the poor profile soil water simulations at Akron in 2005 with triticale.

At both Akron and Sidney in 2004 and 2005, water use (actual evapotranspiration) of the triticale crop increased as soil water at planting increased except at Sidney in 2005 (Felter et al., 2006). Simulated water use by the crop was lower for the Low PAW treatment than for the High PAW treatment by $6.6 \mathrm{~cm}$ in 2004 and by $6.9 \mathrm{~cm}$ in 2005 at Akron, and by $5.5 \mathrm{~cm}$ in 2004 and by $0.7 \mathrm{~cm}$ in 2005 at Sidney following the measured pattern of water use as influenced by initial PAW (data not shown). As such, the capability of the model to accurately simulate the water use and biomass production (forage yield) of triticale suggests that the model may serve as a valuable tool to guide research for increasing water-use efficiency of dryland production systems that include triticale in semi-arid environments, and for extrapolation of research results to other locations, climates, and soils.

\subsection{Proso millet}

\subsubsection{Calibration}

Data for modeling proso millet were limited to two site-years due to crop destruction by hail at Sidney in 2004 and poor emergence at Akron in 2005. The High PAW treatment in 2005 at Sidney was used for calibration of the model. With that treatment, $24.4 \mathrm{~cm}$ PAW was present in the $120 \mathrm{~cm}$ soil profile at planting (Table 1). Simulation of soil water under this treatment resulted in an RMSE of $0.033 \mathrm{~m}^{3} \mathrm{~m}^{-3}$ for volumetric soil water in different soil layers, and an RMSE of $2.2 \mathrm{~cm}$ (MRE $=8 \%$ and $d=0.97$ ) for the $120 \mathrm{~cm}$ soil profile (Table 12, Fig. 4). Taking into account the high spatial variability of soil water in the field, and the uncertainties inherent in measurement and quantification, these simulations are reasonably accurate for correct simulations of the crop. LAI simulations were reasonable with an RMSE of $0.83 \mathrm{~m}^{2} \mathrm{~m}^{-2}$, MRE of $21 \%$, and $d$ of 0.92 (Table 12, Fig. 5). Biomass growth with crop development was simulated well with an RMSE of $411 \mathrm{~kg} \mathrm{ha}^{-1}$, MRE of $6 \%$, and $d$ of 1.00 (Table 12, Fig. 6). Simulation of grain yield at crop physiological maturity was also simulated reasonably well

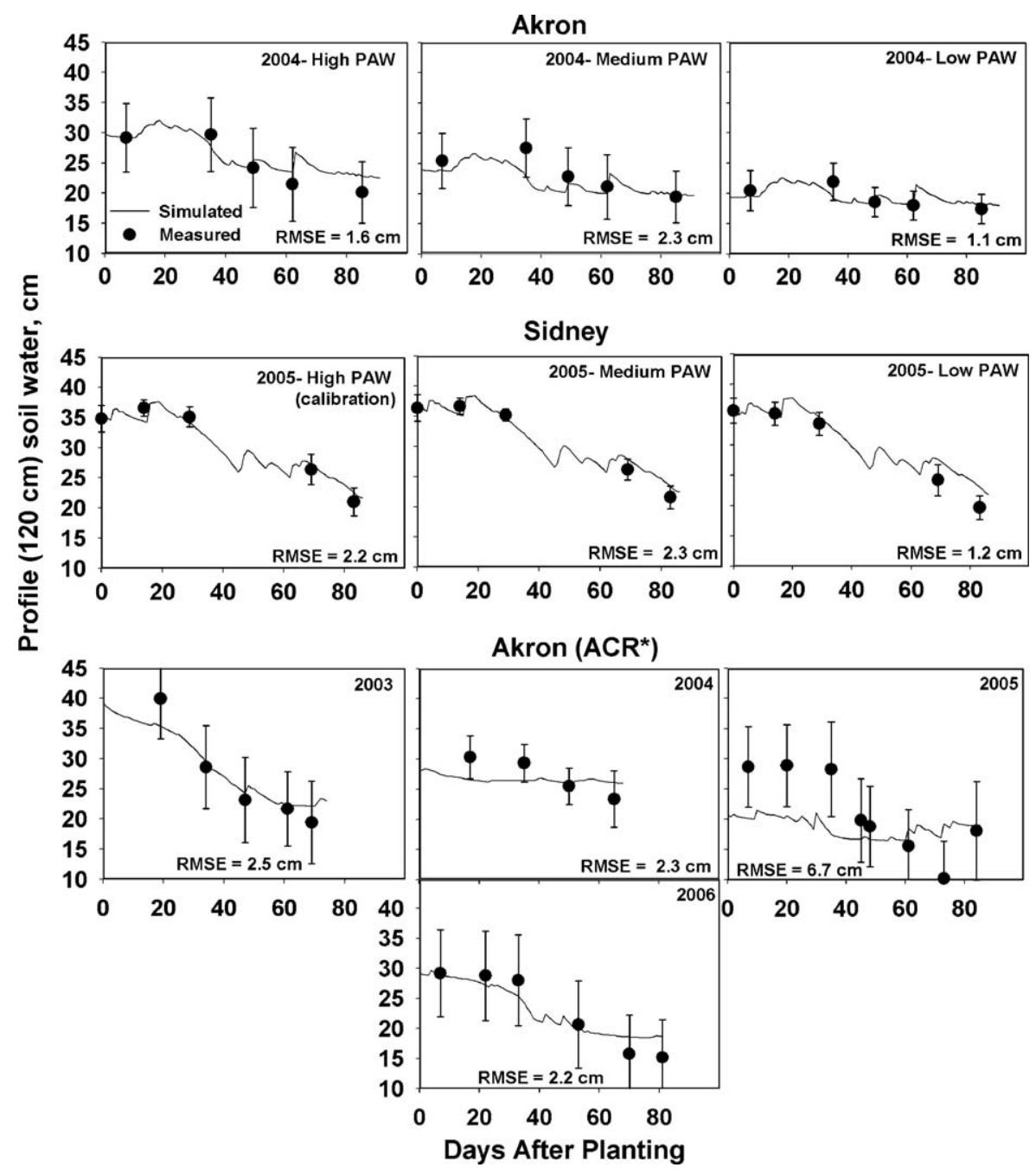

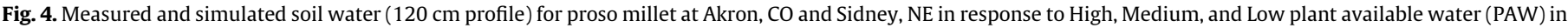

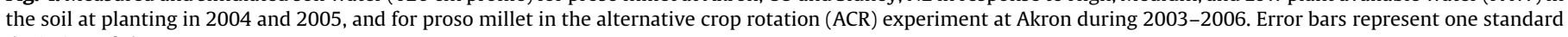
deviation of the mean. 


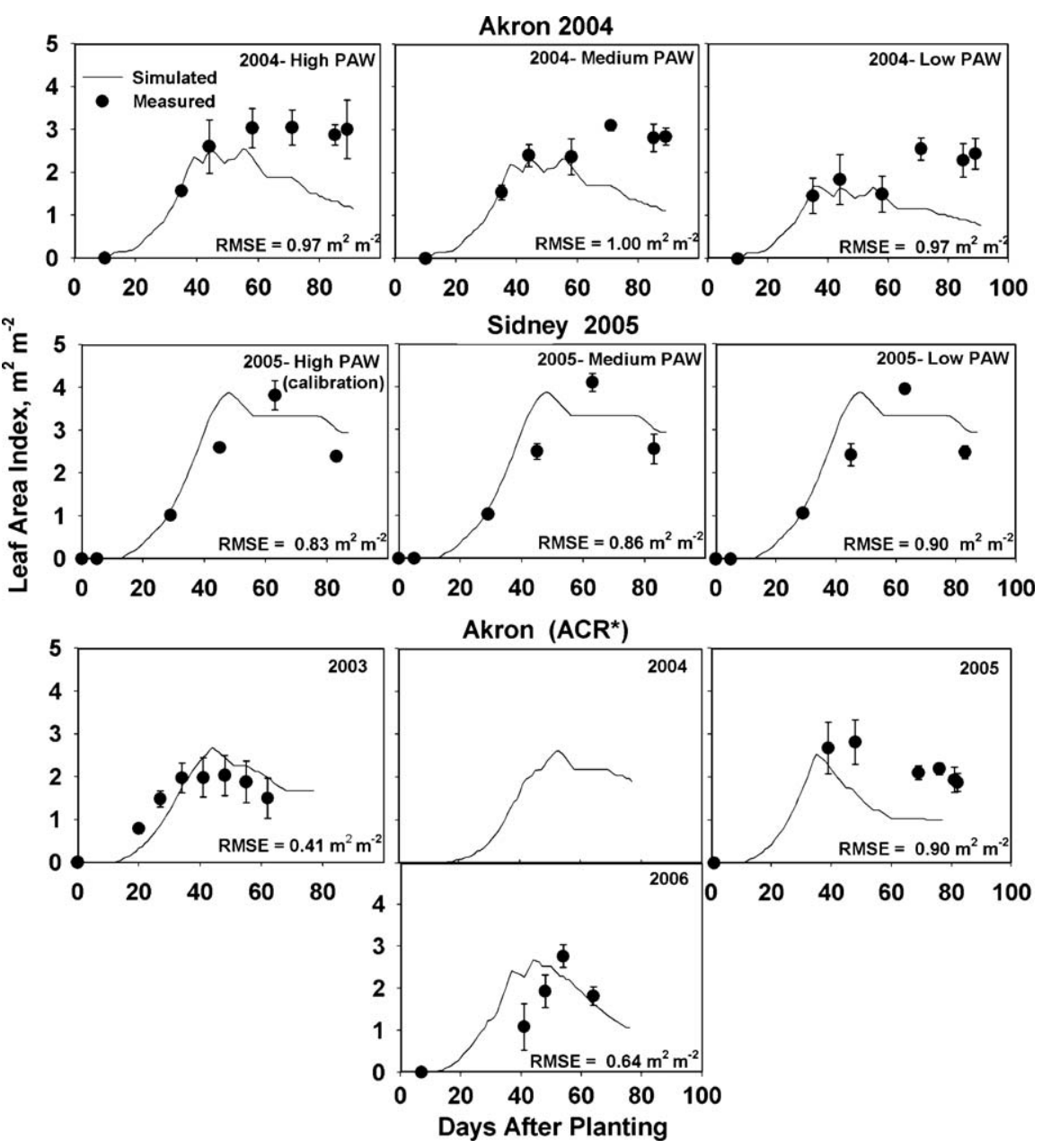

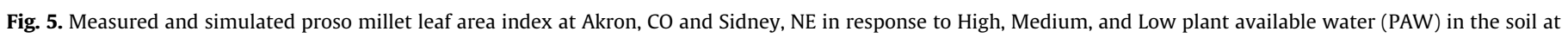

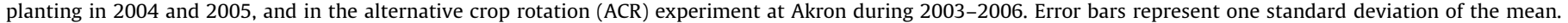

with an MRE of $10 \%$ (simulated value was $428 \mathrm{~kg} \mathrm{ha}^{-1}$ lower than the measured value). The model only simulated a few developmental stages (emergence, anthesis, physiological maturity) such that only crop emergence date was available for comparison of simulated crop phenological development with measured data. The simulated emergence date was 2 days later than the measured emergence date (Table 3).

\subsubsection{Validation}

Soil water amounts and changes with proso millet growth were reasonably simulated across treatments, years, and locations (Fig. 4). Crop biomass, LAI, and grain yield of proso millet increased with initial PAW at Akron in 2004 (Figs. 5-7). The difference in available soil water between High and Low PAW treatments at millet planting in 2004 at Akron was 100 mm. Felter et al. (2006) reported that $58 \%$ of the variability in proso millet grain yield in the experiment was explained by initial PAW. Crop emergence was correctly simulated as 10 days after planting (Table 3 ). However, simulated anthesis date was 7 days later than observed and simulated physiological maturity was 4 days later than observed. These errors in rate of development did not affect the overall simulations of the crop drastically. Soil water was adequately simulated in 2004 with RMSEs between 0.036 and $0.039 \mathrm{~m}^{3} \mathrm{~m}^{-3}$ for the volumetric soil water in different soil layers. Water in the $120 \mathrm{~cm}$ soil profile was simulated with RMSEs between $1.9 \mathrm{~cm}$ (MRE $=6 \%$ and $d=0.92$ ) and $2.5 \mathrm{~cm}$ (MRE $=7 \%$ and $d=0.75$ ) (Table 12 and Fig. 4). Leaf area index in 2004 was simulated less accurately with RMSEs of $0.97 \mathrm{~m}^{2} \mathrm{~m}^{-2}(\mathrm{MRE}=33 \%$ and $d=0.78)$, $1.0 \mathrm{~m}^{2} \mathrm{~m}^{-2}(\mathrm{MRE}=35 \%$ and $d=0.72)$ and $0.97 \mathrm{~m}^{2} \mathrm{~m}^{-2}(\mathrm{MRE}=39 \%$ and $d=0.65$ ) in the High, Medium and Low PAW treatments, respectively (Table 12 and Fig. 5). However, biomass gain with crop development was reasonably well simulated with RMSEs between $588 \mathrm{~kg} \mathrm{ha}^{-1}(\mathrm{MRE}=30 \%$ and $d=0.98)$ in the High PAW treatment and $955 \mathrm{~kg} \mathrm{ha}^{-1}(\mathrm{MRE}=29 \%$ and $d=0.95)$ in the Medium PAW treatment (Table 12 and Fig. 6). Grain yield simulations across the three PAW treatments in 2004 had an RMSE of $196 \mathrm{~kg} \mathrm{ha}^{-1}$ and MRE of $37 \%$. While the grain yields simulated in the High and Medium PAW treatments were simulated with MREs of $2 \%$ and $23 \%$, the grain yield in the Low PAW treatment showed an MRE of $87 \%$. The lower accuracy in grain yield simulations for the Low water treatment in 2004 occurred due to the model's low responsiveness regarding biomass partitioning changes to grain in response to water stress (inaccurately simulating changes to harvest index (HI) that occur in response to water stress). Measured HI for the High, Medium, and Low PAW treatments were $0.23,0.18$ and 0.11 , respectively. However, simulated $\mathrm{HI}$ for all three treatments remained at 0.24 . Further studies are needed to correctly quantify HI changes in response to water stress.

At Sidney in 2005, measured grain yield was not significantly affected by soil water at planting $(P=0.90)$ (Fig. 7), with all treatments yielding about $4000 \mathrm{~kg} \mathrm{ha}^{-1}$. Little difference existed in water availability between treatments in 2005 (Table 1). Also, measured maximum LAI (Fig. 5) and biomass (Fig. 6) in 2005 did not show any significant difference between the High, Medium, 

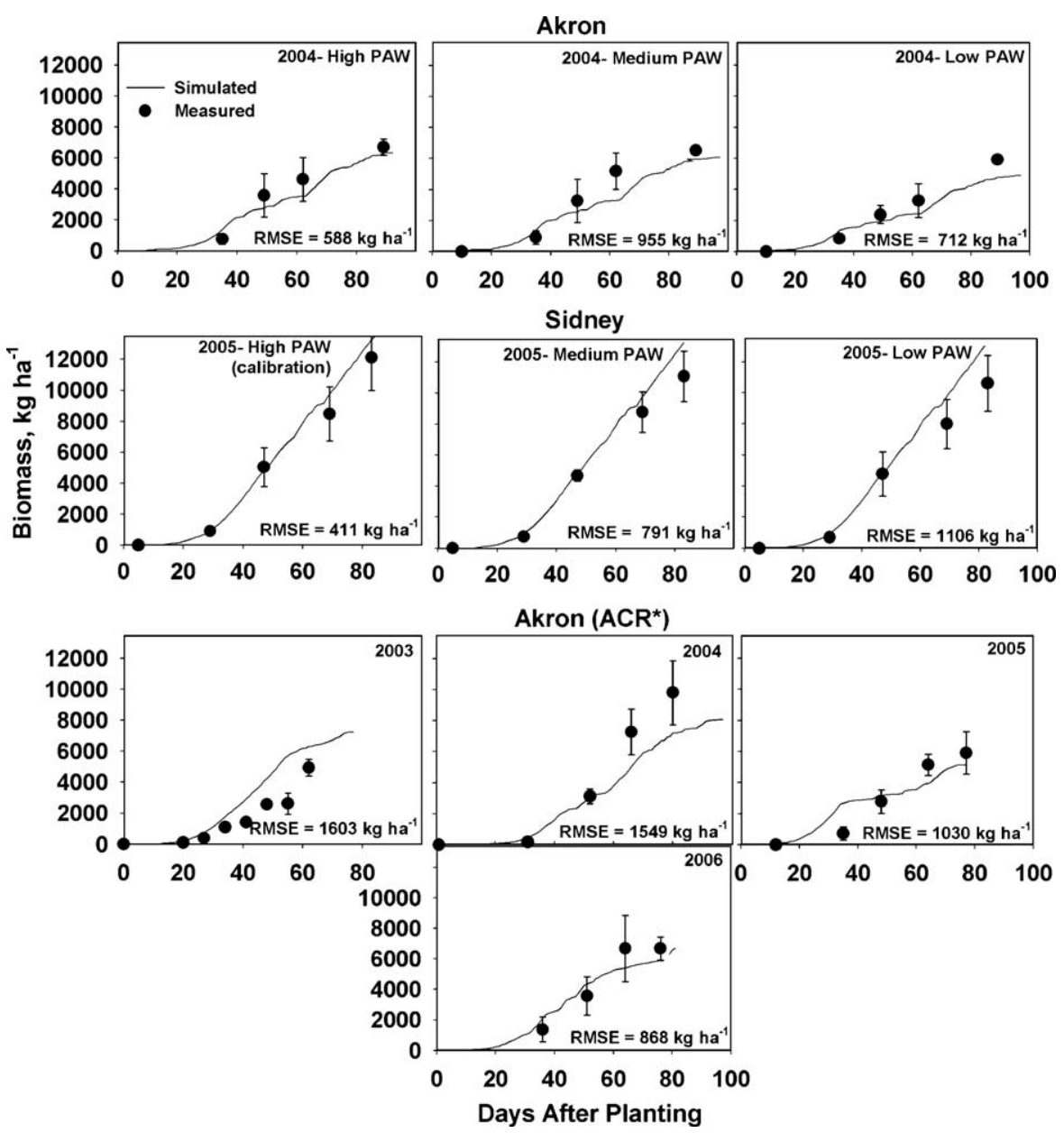

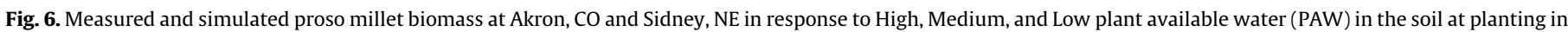
2004 and 2005, and in the alternative crop rotation (ACR) experiment at Akron during 2003-2006. Error bars represent one standard deviation of the mean.

and Low PAW treatments ( $P=0.42$ for LAI, $P=0.52$ for biomass). Simulations of these variables were accurate and also did not show significant differences between the three treatments. For the validation treatments (Medium and Low PAW treatments),

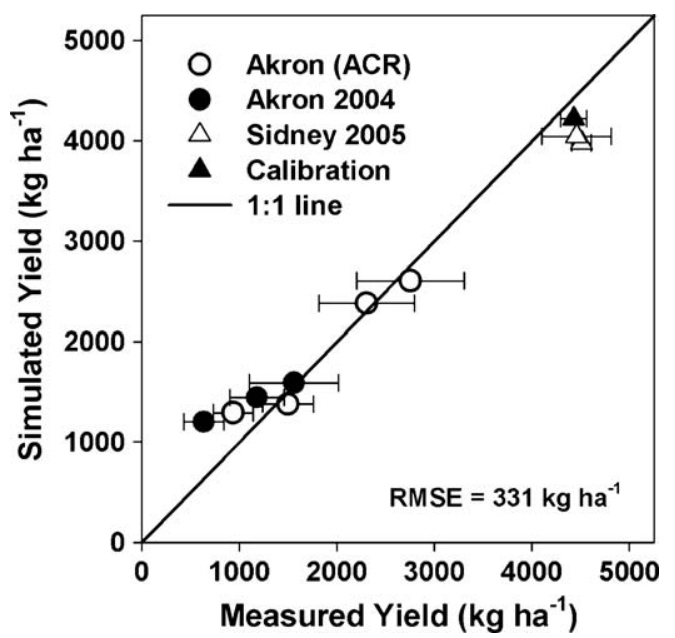

Fig. 7. Measured and simulated proso millet grain yields at Akron, CO and Sidney, NE in response to High, Medium, and Low plant available water in the soil at planting in 2004 and 2005, and in the alternative crop rotation (ACR) experiment at Akron during 2003-2006. Error bars represent one standard deviation of the mean simulations of soil water in different soil layers across treatments resulted in RMSEs between 0.027 and $0.034 \mathrm{~m}^{3} \mathrm{~m}^{-3}$, and simulations of total soil water in the $120 \mathrm{~cm}$ profile resulted in RMSEs between $1.2 \mathrm{~cm}(\mathrm{MRE}=5 \%$ and $d=0.99)$ and $2.3 \mathrm{~cm}(\mathrm{MRE}=8 \%$ and $d=0.97$ ) (Table 12 and Fig. 4). Leaf area index was simulated with RMSEs between $0.86 \mathrm{~m}^{2} \mathrm{~m}^{-2} \quad($ MRE $=36 \%$ and $d=0.92)$ and $0.90 \mathrm{~m}^{2} \mathrm{~m}^{-2}(\mathrm{MRE}=38 \%$ and $d=0.91$ ) (Table 12 and Fig. 5). Biomass accumulation with crop development was well simulated with RMSEs between $791 \mathrm{~kg} \mathrm{ha}^{-1}$ (MRE $=10 \%$ and $d=0.99$ ) in the Medium PAW treatment and $1106 \mathrm{~kg} \mathrm{ha}^{-1} \quad(\mathrm{MRE}=15 \%$ and $d=0.99$ ) in the Low PAW treatment (Table 12 and Fig. 6). Simulated grain yield in 2005 was reasonable with an RMSE of $496 \mathrm{~kg} \mathrm{ha}^{-1}$ and MRE of $9 \%$ (Fig. 7).

The model performance was further tested with proso millet data from the ACR experiments at Akron from 2003 to 2006 (Anderson et al., 1999; Nielsen, unpublished data, 2006). In these experiments initial PAW varied from year to year as a result of previous crop water use and non-crop period precipitation (in contrast to the varying initial water contents created by pre-season irrigation described for the previously discussed experiments). Soil water measurements in these experiments across years showed high variability between replications as reflected in the high standard deviations of individual measurements from the mean (Fig. 4). However, the model simulated soil water in these experiments adequately (within one standard deviation of the treatment means) with the exception of 2005. For this year, similar large errors in the simulation were noticed as with the triticale 
Table 13

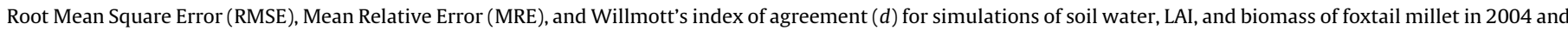
2005 at Akron, CO and Sidney, NE in response to High, Medium, and Low plant available water (PAW) in the soil at planting.

\begin{tabular}{|c|c|c|c|c|c|c|c|c|c|}
\hline \multirow[t]{2}{*}{ Variables } & \multicolumn{3}{|l|}{ High PAW } & \multicolumn{3}{|c|}{ Medium PAW } & \multicolumn{3}{|c|}{ Low PAW } \\
\hline & RMSE & MRE, \% & $d$ & RMSE & MRE, \% & $d$ & RMSE & MRE, \% & $d$ \\
\hline \multicolumn{10}{|l|}{ Akron 2004} \\
\hline Soil water, $\mathrm{m}^{3} \mathrm{~m}^{-3}$ & $0.030^{\mathrm{a}}$ & - & - & 0.032 & - & - & 0.023 & - & - \\
\hline Soil profile water, $\mathrm{cm}$ & $1.5^{\mathrm{a}}$ & $5^{\mathrm{a}}$ & $0.92^{\mathrm{a}}$ & 2.9 & 9 & 0.73 & 1.5 & 5 & 0.81 \\
\hline LAI, $\mathrm{m}^{2} \mathrm{~m}^{-2}$ & $0.79^{\mathrm{a}}$ & $20^{\mathrm{a}}$ & $0.95^{\mathrm{a}}$ & 0.68 & 24 & 0.95 & 0.57 & 27 & 0.93 \\
\hline Biomass, $\mathrm{kg} \mathrm{ha}^{-1}$ & $194^{\mathrm{a}}$ & $10^{a}$ & $1.00^{\mathrm{a}}$ & 444 & 21 & 0.98 & 709 & 20 & 0.95 \\
\hline \multicolumn{10}{|l|}{ Sidney 2005} \\
\hline Soil water, $\mathrm{m}^{3} \mathrm{~m}^{-3}$ & 0.025 & - & - & 0.028 & - & - & 0.021 & - & - \\
\hline Soil profile water, $\mathrm{cm}$ & 1.3 & 4 & 0.98 & 1.2 & 3 & 0.98 & 0.3 & 1 & 1.00 \\
\hline LAI, $\mathrm{m}^{2} \mathrm{~m}^{-2}$ & 0.86 & 34 & 0.96 & 0.87 & 29 & 0.97 & 1.0 & 48 & 0.95 \\
\hline Biomass, $\mathrm{kg} \mathrm{ha}^{-1}$ & 336 & 22 & 1.00 & 298 & 27 & 1.00 & 201 & 9 & 1.00 \\
\hline
\end{tabular}

a Calibration results.

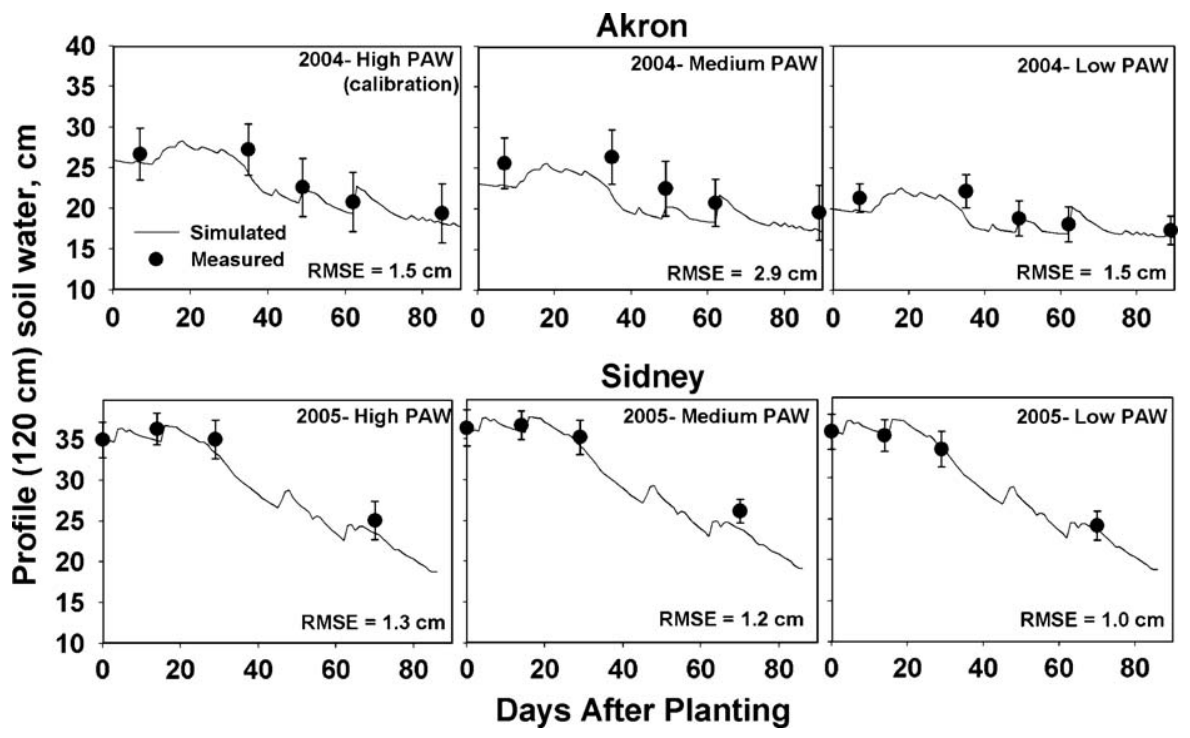

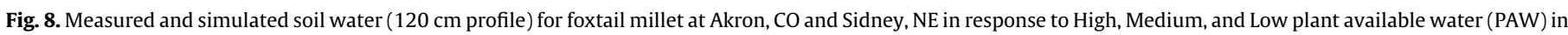
the soil at planting in 2004 and 2005. Error bars represent one standard deviation of the mean.

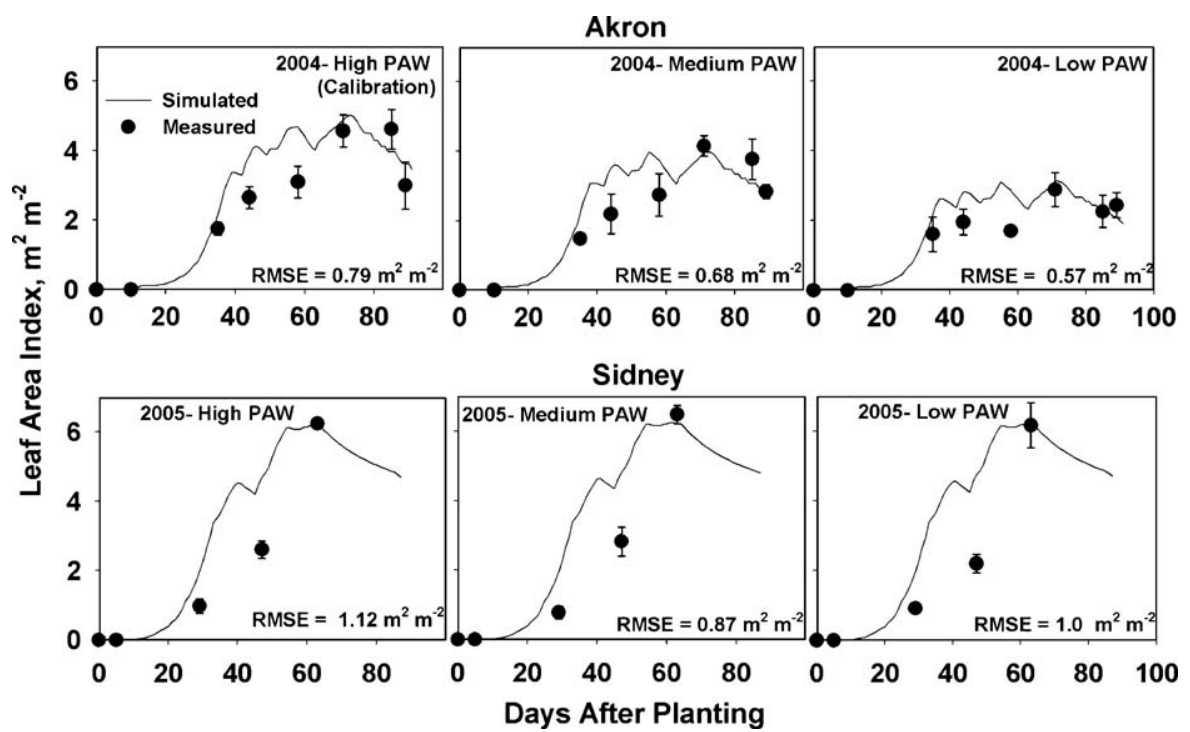

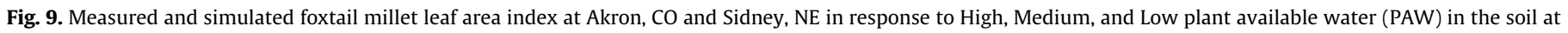
planting in 2004 and 2005. Error bars represent one standard deviation of the mean. 
crop discussed above. We are currently without an explanation for why the model performed so poorly relative to profile soil water simulations in 2005 at Akron. Total profile soil water contents during the four years of the ACR experiments were simulated with RMSEs of $2.2(\mathrm{MRE}=6 \%$ and $d=0.96)$ in 2003, $2.3 \mathrm{~cm}(\mathrm{MRE}=10 \%$ and $d=0.91)$ in 2004, $6.7 \mathrm{~cm}(\mathrm{MRE}=21 \%$ and $d=0.38)$ in 2005, and $2.2 \mathrm{~cm}(\mathrm{MRE}=9 \%$ and $d=0.95)$ in 2006 (Table 12 and Fig. 4).

There were no LAI measurements made in the ACR experiment in 2004. LAI simulations in the remaining years had RMSEs between 0.41 and $0.89 \mathrm{~m}^{2} \mathrm{~m}^{-2}$ (Fig. 5). Biomass simulations resulted in RMSEs of $1603 \mathrm{~kg} \mathrm{ha}^{-1}(\mathrm{MRE}=80 \%$ and $d=0.85$ ), $1549 \mathrm{~kg} \mathrm{ha}^{-1}(\mathrm{MRE}=20 \%$ and $d=0.95), 1030 \mathrm{~kg} \mathrm{ha}^{-1}(\mathrm{MRE}=19 \%$ and $d=0.94)$, and $868 \mathrm{~kg} \mathrm{ha}^{-1}(\mathrm{MRE}=22 \%$ and $d=0.97$ ) for 2003 , 2004, 2005, and 2006, respectively (Table 12 and Fig. 6). These errors were higher than those observed in the PAW experiments with proso millet discussed above. In response to the poor soil water simulations in 2005, grain yield simulations showed higher RMSEs compared with other years. Simulated grain yield in 2005 was $352 \mathrm{~kg} \mathrm{ha}^{-1}$ greater than observed and had an MRE of 37\%, while MREs and differences between simulated and observed yields were smaller in 2003, 2004, and 2006 (Table 12 and Fig. 7). Improvements in soil water simulations by the model may lead to improvements in crop growth and yield simulations. Grain yield simulations in all four years of the ACR experiments showed an RMSE of $205 \mathrm{~kg} \mathrm{ha}^{-1}$ with an MRE of $14 \%$. Considering the results of all of the simulations conducted, the model predictions were considered sufficiently accurate for further use in the development of decision support tools for managing proso millet in the region.

\subsection{Foxtail millet}

\subsubsection{Calibration}

Foxtail millet, like proso millet, was also affected by hail and emergence problems resulting in only two site-years available for calibration and validation. Foxtail millet is generally grown for hay/forage in the United States (Baltensperger, 1996). As with the triticale crop discussed above, foxtail millet was therefore also harvested for forage in the current experiments. The High PAW treatment at Akron in 2004 was used for calibration of the model with the remaining data sets used for model validation. Foxtail millet dry matter increased linearly with available soil water at planting at Akron in 2004 (Felter et al., 2006). Soil water was simulated well in the calibration data set (High PAW treatment) with an RMSE of $0.03 \mathrm{~m}^{3} \mathrm{~m}^{-3}$ for volumetric soil water in different soil layers, and with an RMSE of $1.5 \mathrm{~cm}(\mathrm{MRE}=5 \%$ and $d=0.92)$ for total soil water in the $120 \mathrm{~cm}$ soil profile (Table 13, Fig. 8). Simulated LAI had an RMSE of $0.79 \mathrm{~m}^{2} \mathrm{~m}^{-2}$ (MRE $=20 \%$ and $d=0.95$ ), adequately replicating the measured pattern (Fig. 9). The time progression of biomass measured in the experiment was also well simulated with an RMSE of $194 \mathrm{~kg} \mathrm{ha}^{-1}$ (MRE $=10 \%$ and $d=1.00$ ) (Table 13 and Fig. 10). Emergence date was the only crop phenology data available for comparison with the simulations. In the model calibration data set, crop emergence was simulated to occur 8 days after planting while emergence was observed to occur in the field 10 days after planting.

\subsubsection{Validation}

The foxtail millet crop at Akron in 2004 was water-limited. The difference in available soil water at planting between High and Low treatments was $63 \mathrm{~mm}$ (Table 1). Maximum LAI and dry matter declined with decreasing available soil water at planting (Figs. 9 and 10). At Akron, dry matter yield increased linearly with initial PAW explaining $62 \%$ of the variability in dry matter yield in this year (Felter et al., 2006). The Medium and Low PAW treatments at Akron in 2004 were used for testing the calibrated model. Soil water was adequately simulated in these treatments with RMSEs of 0.023 and $0.032 \mathrm{~m}^{3} \mathrm{~m}^{-3}$ for the volumetric water in different soil layers, respectively. Water in the $120 \mathrm{~cm}$ soil profile was simulated with RMSEs of 1.5 (MRE $=5 \%$ and $d=0.81$ ) for the Low PAW treatment and $2.9 \mathrm{~cm}$ (MRE $=9 \%$ and $d=0.73$ ) for the Medium PAW treatment (Table 13 and Fig. 8). The model adequately simulated the decline of both LAI and biomass with decreasing initial PAW (Figs. 9 and 10). LAI simulations showed RMSEs of $0.68 \mathrm{~m}^{2} \mathrm{~m}^{-2}($ MRE $=24 \%$ and $d=0.95)$ in the Medium treatment and $0.57 \mathrm{~m}^{2} \mathrm{~m}^{-2}(\mathrm{MRE}=27 \%$ and $d=0.93)$ in the Low treatment (Table 13 and Fig. 9). Biomass progression with time in these treatments also was well simulated with most of the individual simulated values falling within one standard deviation of the mean measured values (Fig. 10). However, simulated biomass had RMSEs of $444 \mathrm{~kg} \mathrm{ha}^{-1}(\mathrm{MRE}=21 \%$ and $d=0.98)$ and $709 \mathrm{~kg} \mathrm{ha}^{-1}$ (MRE $=20 \%$ and $\left.d=0.95\right)$, respectively, for Medium and Low PAW treatments.

Water content in the soil profile at planting was similar in all water treatments at Sidney in 2005, and adequate precipitation was received during the growing season in 2005 (Tables 1 and 10). As such, there was not a significant response of crop growth and

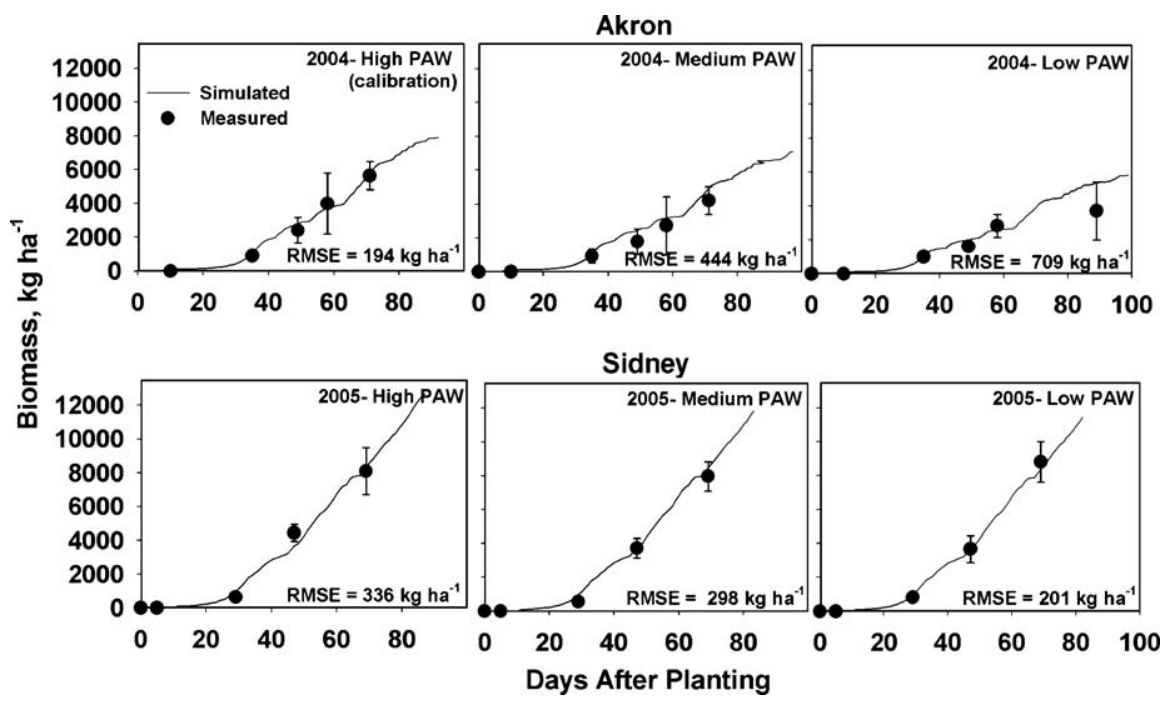

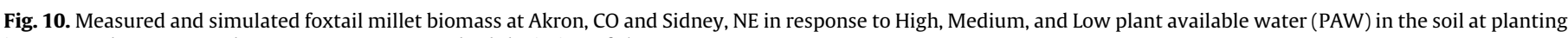
in 2004 and 2005. Error bars represent one standard deviation of the mean. 
development to soil water at planting across different PAW treatments. Simulated crop emergence occurred 7 days after planting compared with observed emergence 5 days after planting (Table 3). Soil water was accurately simulated at Sidney in 2005 leading to reasonably accurate simulations of maximum LAI and biomass development in the three PAW treatments (Figs. 8, 9 and 10). Soil water in different soil layers was simulated with an RMSE between 0.021 and $0.028 \mathrm{~m}^{3} \mathrm{~m}^{-3}$ for the three treatments (Table 13). Total PAW in the soil profile was simulated with an RMSE of $1.3 \mathrm{~cm}$ or less and an MRE of $4 \%$ or less in the three treatments. RMSEs of LAI simulations ranged between $1.0 \mathrm{~m}^{2} \mathrm{~m}^{-2}$ (MRE $=48 \%$ and $d=0.95)$ and $0.86 \mathrm{~m}^{2} \mathrm{~m}^{-2} \quad(\mathrm{MRE}=34 \%$ and $d=0.96$ ) (Table 13). Mid-season LAI was over-predicted by the model. Simulations of the time progression of biomass matched well with the measurements resulting in RMSEs below $336 \mathrm{~kg} \mathrm{ha}^{-1}$ and MREs below 27\% across the three treatments (Table 13 and Fig. 10). In general, validation of the model simulations with limited data (one year each at two locations) showed that foxtail millet and its responses to different initial PAW could be satisfactorily predicted with the model developed.

\section{Summary and conclusions}

Wheat farmers in the Great Plains could benefit greatly from the availability of a short-season crop that could be produced during the spring or summer months prior to planting the next wheat crop in late September or early October. Experiments with triticale and foxtail millet as forage crops and proso millet as a grain/forage crop showed the potential of these short-season crops for use in a flexible summer fallow cropping system, and the amount of plant available water in the soil at planting may be a significant indicator of subsequent yield (Felter et al., 2006). However, these relationships can vary between seasons and locations depending on the amount and distribution of growing season precipitation and other weather variables experienced subsequent to planting. The models developed for simulation of these three crops are potential tools that can integrate and synthesize information from such shortseason experiments and effectively extend the results to other seasons, soils, and climates (e.g., for selection of the crop best suited in a particular season at a particular location). For simulation of these crops, the DSSAT v4.0 crop simulation modules as available in RZWQM2-DSSAT v4.0 were successfully adapted and calibrated using the crop growth and development data collected from experiments at Sidney, NE and Akron, CO. The CSMCERES-Wheat v4.0 module was adapted for simulation of spring triticale, and the CSM-CERES-Sorghum module was adapted for simulation of both proso millet and foxtail millet. Specifically, the species and ecotype parameters for the crops in the CSM modules were adapted for simulation of the crops. Each crop module was further calibrated for cultivar traits (genetic coefficients) for simulating the specific crop cultivars used in the experiments. The three crop modules developed for spring triticale, proso millet, and foxtail millet all simulated crop growth and development well and also adequately responded to different levels of PAW in the soil at planting in different years (2004 and 2005) and at different locations (Sidney and Akron). Because spring triticale and foxtail millet were harvested for forage before reaching physiological maturity, the models developed for these two crops could not be tested for simulation of grain yield. Further experiments are required to grow these crops to full maturity, and measure the grain yields for calibration and validation of the model simulations. The crop modules developed in this study have shown adequate potential for future simulations of these crops in rotations with other crops in northeastern Colorado and western Nebraska. Further testing should be done to validate these models for different soil types and climates (locations) so that these models can be used for decision support relating to crop management throughout the High Plains. Developing decision support for selection of the best suited short-season summer crop in a crop rotation in a particular season at a location based on measured initial PAW in the soil by using RZWQM2-DSSATV4.0 and historical climate records would be a challenging example of the application of the model in strategic farm management, and will be taken up and reported in subsequent studies.

\section{References}

Ahuja, L.R., Rojas, K.W., Hanson, J.D., Shafer, M.J., Ma, L. (Eds.), 2000. Root Zone Water Quality Model: Modeling Management Effects on Water Quality and Crop Production. Water Resources Publications, LLC, CO, USA, p. 372.

Andales, A.A., Ahuja, L.R., Peterson, G.A., 2003. Evaluation of GPFARM for dryland cropping systems in eastern Colorado. Agron. J. 95, 1510-1524.

Anderson, R.L., 1994. Planting date effects on no-till proso millet. J. Prod. Agric. 7, 454-458.

Anderson, R.L., Bowman, R.A., Nielsen, D.C., Vigil, M.F., Aiken, R.M., Benjamin, J.G., 1999. Alternative crop rotations for the central Great Plains. J. Prod. Agric. 12 95-99.

Baltensperger, D.D., 1996. Foxtail and proso millet. In: Janick, J. (Ed.), Progress in New Crops. ASHS Press, Alexandria, VA, pp. 182-190.

Clarke, M.L., Rendell, H.M., 2003. Late Holocene dune accretion and episodes of persistent drought in the Great Plains of northeastern Colorado. Quaternary Sci. Rev. 22, 1051-1058.

DeVuyst, E.A., Halvorson, A.D., 2004. Economics of annual cropping versus cropfallow in the northern Great Plains as influenced by tillage and nitrogen. Agron. J. 96, 148-153.

Dhuyvetter, K.C., Thompson, C.R., Norwood, C.A., Halvorson, A.D., 1996. Economics of dryland cropping systems in the Great Plains: a review. J. Prod. Agric. 9, 216222.

Elliott, E.T., Cole, C.V., 1989. A perspective on agroecosystem science. Ecology 70 , 1597-1602.

Ewert, F., Porter, J., Honermeier, B., 1996. Use of AFRCWHEAT2 to predict the development of main stem and tillers in winter triticale and winter wheat in North East Germany. Eur. J. Agron. 5, 89-103.

Farahani, H.J., Peterson, G.A., Westfall, D.G., Sherrod, L.A., Ahuja, L.R., 1998. Soil water storage in dryland cropping systems: the significance of cropping intensification. Soil Sci. Soc. Am. J. 62, 984-991.

Felter, D.G., Lyon, D.J., Nielsen, D.C., 2006. Evaluating crops for a flexible summer fallow cropping system. Agron. J. 98, 1510-1517.

Gallagher, J.N., 1979. Field studies of cereal leaf growth. I. Initiation and expansion in relation to temperature and ontogeny. J. Exp. Bot. 117, 625-636.

Halvorson, A.D., 1990. Cropping systems and $\mathrm{N}$ fertilization for efficient water use in the central Great Plains. Agric. Counc. Bull. 131, 117-123.

Halvorson, A.D., Peterson, G.A., Reule, C.A., 2002a. Tillage system and crop rotation effects on dryland crop yields and soil carbon in the central Great Plains. Agron. J. 94, 1429-1436.

Halvorson, A.D., Wienhold, B.J., Black, A.L., 2002b. Tillage, nitrogen, and cropping system effects on soil carbon sequestration. Soil Sci. Soc. Am. J. 66, 906-912.

Hoogenboom, G., Wilkens, P.W., Tsuji, G.Y., 1999. Decision Support System for Agrotechnology Transfer (DSSAT) v.3, vol. 4. University of Hawaii, Honolulu.

Hoogenboom, G., Jones, J.W., Wilkens, P.W., Porter, C.H., Batchelor, W.D., Hunt, L.A., Boote, K.J., Singh, U., Uryaswv, O., Bowen, W.T., Gijsman, A., DuToit, A., White, J.W., Tsuji, G.Y., 2004. Decision support systems for agrotechnology transfer version 4.0. CD-ROM. ICASA, Honolulu, $\mathrm{HI}$.

Jones, J.W., Hoogenboom, G., Porter, C.H., Boote, K.J., Batchelor, W.D., Hunt, L.A., Wilkens, P.W., Singh, U., Gijsman, A.J., Ritchie, J.T., 2003. The DSSAT cropping system model. Eur. J. Agron. 18, 235-265.

Lal, R., Kimble, J.M., Follett, R.F., Cole, C.V., 1998. The Potential of US Cropland to Sequester Carbon and Mitigate the Greenhouse Effect. Sleeping Bear Press, Ann Arbor, MI, p. 128.

Lyon, D.J., Baltensperger, D.D., 1993. Proso millet (Panicum miliaceum) tolerance to several postemergence herbicides. Weed Technol. 7, 230-233.

Lyon, D.J., Baltensperger, D.D., Blumenthal, J.M., Burgener, P.A., Harveson, R.M. 2004. Eliminating summer fallow reduces winter wheat yields, but not necessarily system profitability. Crop Sci. 44, 855-860.

Lyon, D.J., Nielsen, D.C., Felter, D.G., Burgener, P.A., 2007. Choice of summer fallow replacement crops impacts subsequent winter wheat. Agron. J. 99, 578-584.

Ma, L., Hoogenboom, G., Ahuja, L.R., Nielsen, D.C., Ascough II, J.C., 2005. Evaluation of the RZWQM-CROPGRO hybrid model for soybean production. Agron. J. 97, 1172-1182.

Ma, L., Hoogenboom, G., Ahuja, L.R., Ascough II, J.C., Saseendran, S.A., 2006. Evaluation of the RZWQM-CERES-Maize hybrid model for maize production. Agric. Sys. 87, 274-295.

Ma, L., Nielsen, D.C., Ahuja, L.R., Malone, R.W., Saseendran, S.A., Rojas, K.W., Hanson, J.D., Benjamin, J.G., 2003. Evaluation of RZWQM under varying irrigation levels in eastern Colorado. Trans. ASAE 46, 39-49.

Mathews, R., Stephens, W., Hess, T., Middleton, T., Graves, A., 2002. Applications of crop/soil simulation models in tropical agricultural systems. Adv. Agron. 76, 31-124. 
Meko, D.M., Woodhouse, C.A., 2005. Tree-ring footprint of joint hydrologic drought in Sacramento and upper Colorado river basins, western US. J. Hydrol. 308, 196213.

Nielsen, D.C., Aiken, R.M., 1998. Wind speed above and within sunflower stalks varying in height and population. J. Soil Water Conserv. 53, 347-352.

Nielsen, D.C., Anderson, R.L., Bowman, R.A., Aiken, R.M., Vigil, M.F., Benjamin, J.G., 1999. Winter wheat and proso millet yield reduction due to sunflower in rotation. J. Prod. Agric. 12, 193-197.

Nielsen, D.C., Unger, P.W., Miller, P.R., 2005. Efficient water use in dryland cropping systems in the Great Plains. Agron. J. 97, 364-372.

Nielsen, D.C., Vigil, M.F., 2005. Legume green fallow effect on soil water content at wheat planting and wheat yield. Agron. J. 97, 684-689.

Nielsen, D.C., Vigil, M.F., Anderson, R.L., Bowman, R.A., Benjamin, J.G., Halvorson, A.D., 2002. Cropping system influence on planting water content and yield of winter wheat. Agron. J. 94, 962-967.

Peterson, G.A., Halvorson, A.D., Havlin, J.L., Jones, O.R., Lyon, D.J., Tanaka, D.L., 1998. Reduced tillage and increasing cropping intensity in the Great Plains conserves soil C. Soil Till. Res. 47, 207-218.

Peterson, G.A., Westfall, D.G., 2004. Managing precipitation use in sustainable dryland agroecosystems. Ann. Appl. Biol. 144, 127-138.
Ratliff, L.F., Ritchie, J.T., Cassel, D.K., 1983. A survey of field-measured limits of soil water availability and related laboratory-measured properties. Soil Sci. Soc. Am. J. 47, 770-775.

Ritchie, J.T., 1981. Soil water availability. Plant Soil 58, 327-338.

Saseendran, S.A., Ma, L., Nielsen, D.C., Vigil, M.F., Ahuja, L.R., 2005a. Simulating planting date effects on corn production using RZWQM and CERES-Maize. Agron. J. 97, 58-71.

Saseendran, S.A., Nielsen, D.C., Ma, L., Ahuja, L.R., Halvorson, A.D., 2004. Modeling nitrogen management effects on winter wheat production using RZWQM and CERES-wheat. Agron. J. 96, 615-630.

Saseendran, S.A., Nielsen, D.C., Ma, L., Ahuja, L.R., Vigil, M.F., Halvorson, A.D., 2005b. Effectiveness of RZWQM for simulating alternative Great Plains cropping systems. Agron. J. 97, 1183-1193.

Singer, J.W., Sauer, T.J., Blaser, B.C., Meek, D.W., 2007. Radiation use efficiency in dual winter cereal-forage production systems. Agron. J. 99, 1175-1179.

Tsuji, G.Y., Uehara, G., Balas, S. (Eds.), 1994. DSSAT Version 3. International Benchmark Sites Network for Agrotechnology Transfer, vol. 2. Univ. of Hawaii, Honolulu, HI, USA.

Williams, J.R., Jones, C.A., Kiniry, J.R., Spanel, D.A., 1989. The EPIC crop growth model. Trans. ASAE 32, 497-511.

Willmott, C.J., 1981. On the validation of models. Phys. Geogr. 2, 184-194. 